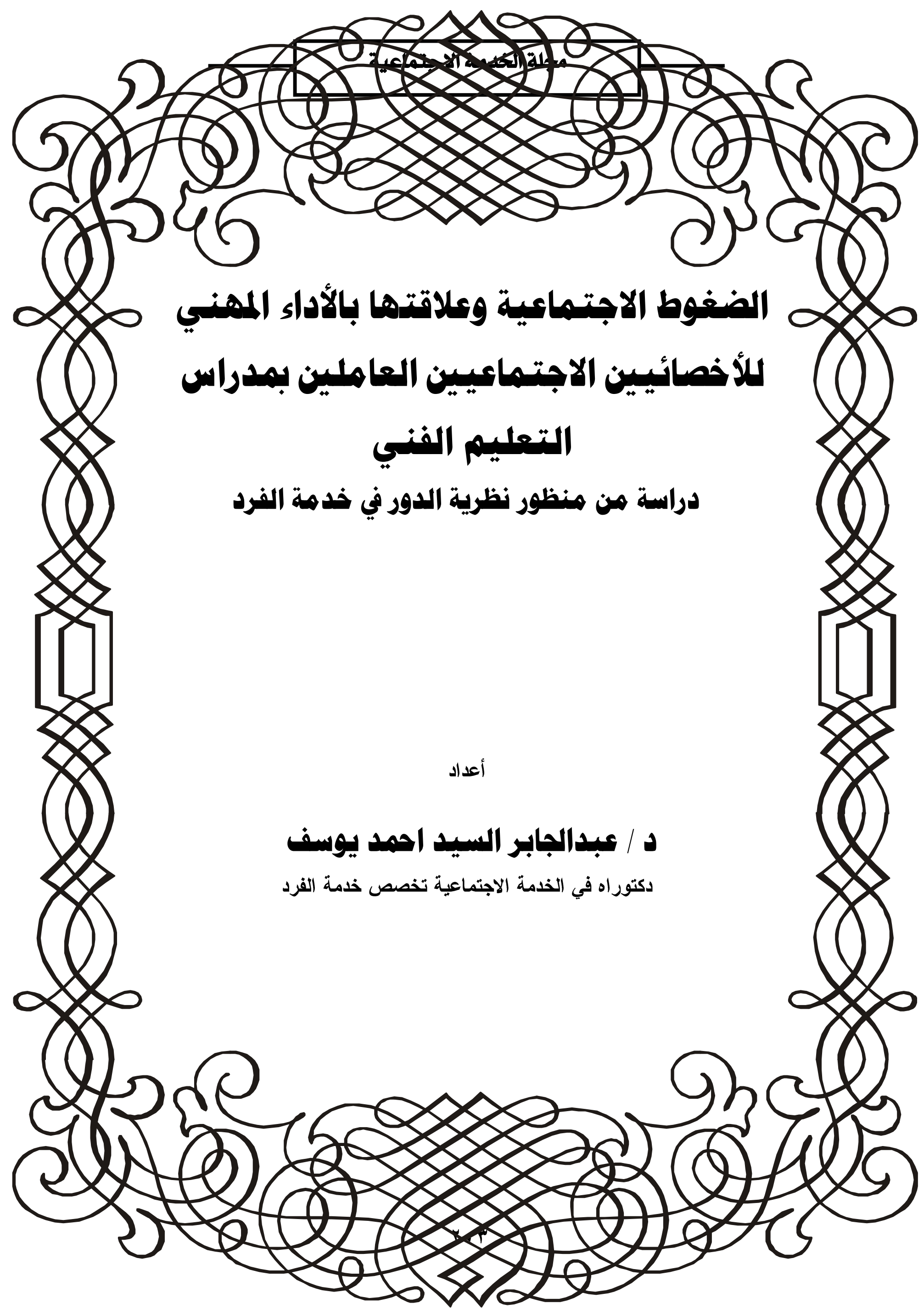




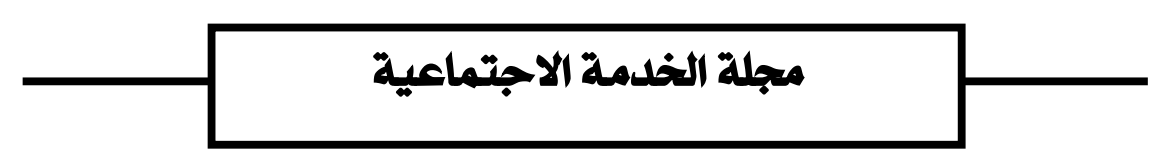

$p \cdot \varepsilon$ 


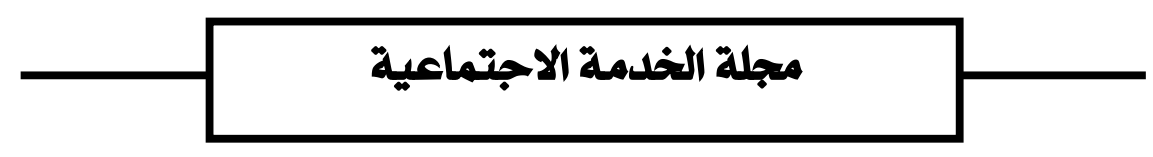

أولا : مشكلة الار اسة : لم تبدأ الوظيفة الاجتماعية للمؤسسة التعليمية حديثاً مع ظهور المهن الاجتماعية المتخصصة و إنما ظهرت هذه الوظيفة مع نثأة المؤسسة التعليمية نفسها منذ القدم باعتبار أن التعليم ذاته يحقق وظيفة اجتماعية إلا إن الجديد المبذول لتحقيقها اقتصر حتى ظهور المهن الاجتماعية المتخصصة علي مجرد رعاية مدرسية إنسانية لا تتسم بالتخطيط أو التخصصية.

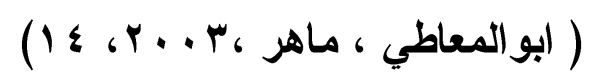

فالخدمة الاجتماعية تمارس في المدرسة لأنه لا يمكن الحصول علي الخدمة للطلاب إلا من خلال

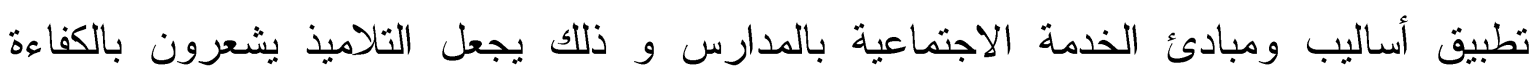
ومواصلة التعليم والقدرة علي التكيف والتغير علي نحو مثزايد ويجب التركيز علي الخدمة الاجتماعية بالمدارس لأنها تركز علي التعلم و التفكير وحل المشكلات وكذلك المجالات التقليدية

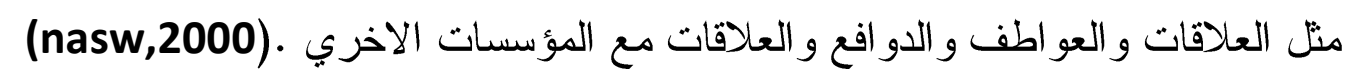

ويتضح لنا أن وجود الأخصائي الاجتماعي بالمدرسة ضرورة اقتضتها سياسة التوســع فــي التعلــيم

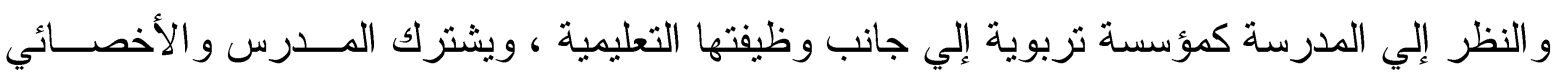

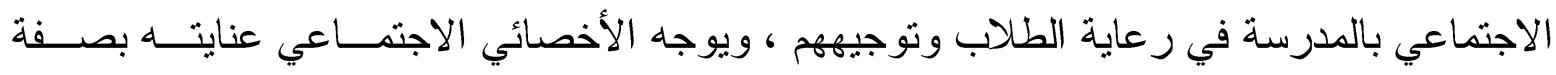

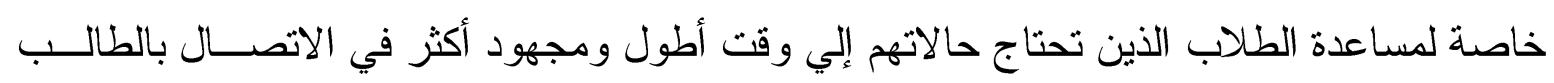

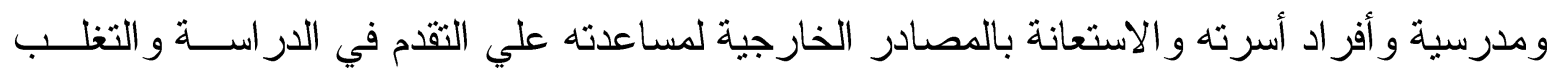

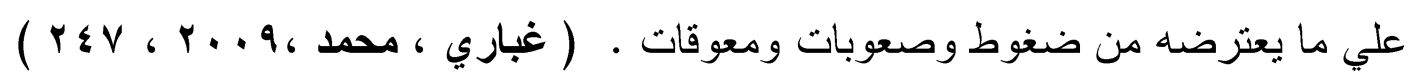
و الظو اهر المجتمعية انطلاقا من الأهداف المعاصرة للتزبية و التعليم فإن الخدمات الفردية تعمل فـي إطار محاور ثلاثة رئيسية هي :

المنظور العلاجي , المنظور الوقائي , والمنظور التتموي ووفقا لهذه المحاور الثلاثة يمكننا تحديد

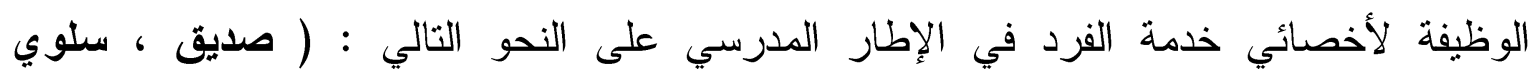
$\left(1 r_{6}, r_{\text {... r }}\right.$ أ-الدور العلاجي : n

يتمثل الدور العلاجي لأخصائي خدمة الفرد المدرسية في معاونة الطالب على مواجهة ما يقابله من مشكلات تعوق انتظام حياته المدرسية. 


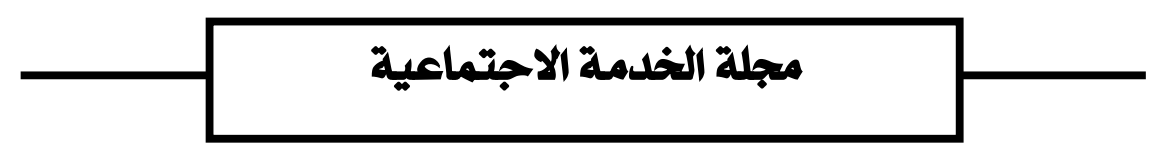

ب - الاور الوقائي : - n

يتمثل الدور الوقائي لأخصائي خدمة الفرد المدرسية في مساعدة الطالب على الحد من

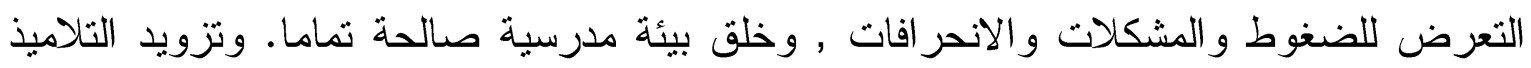

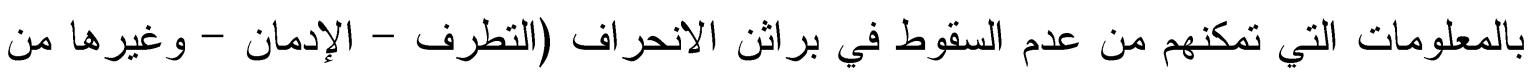
(المشكلات)

$$
\text { ج - الاور التنموي : le }
$$

يتمثل الدور التتموي لأخصائي خدمة الفرد المدرسية في مساعدة الطلاب على اســتمار

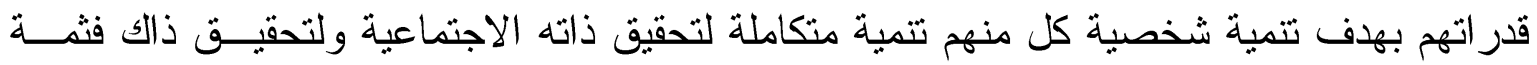

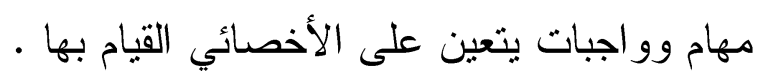
وتعد طريقة خدمة الفرد أحدي الطرق الأساسية للخدمة الاجتماعية التي تحقق علاجُ فعال

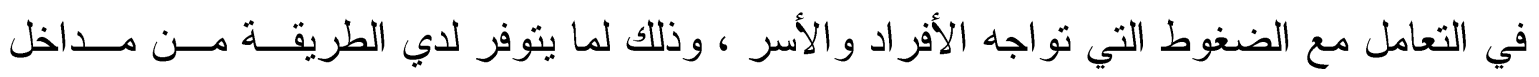

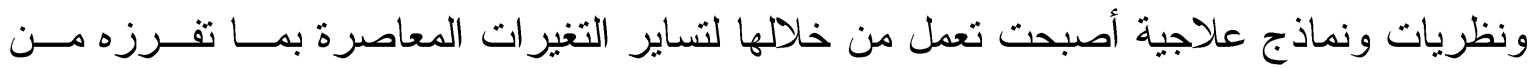

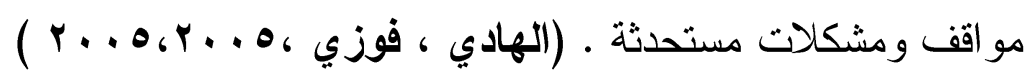
ومن هنا تكمن أهمية خدمة الفرد في المجال التعليمي كما أوضحها عبد الفتاح عثمان :- ( عثمان

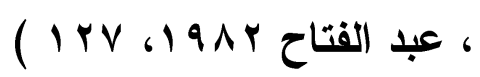
1- إعداد الطلاب اجتماعياً ونفسياً للاستفادة من العملية التعليمية بحل كافة ما يعانون منه من

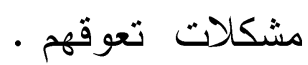

r- مساعدة المدرسة في للتعرف علي مو اقف الطلاب باستجلاء ظروفهم الخاصة وتقديمها

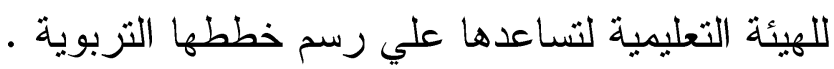

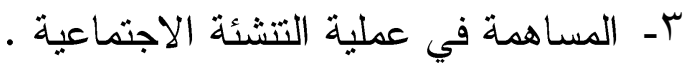
ع- استفادة التلاميذ من خدمات المجتمع الخارجي المتاحة. 0- خدمة الفرد المدرسية يمكن ان تمند جهودها الي العلاج النفسي لبعض الحالات عند غياب

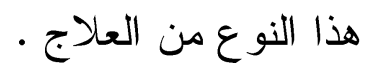
و الضغوط بكل أنوعها هي نتاج الثقدم الحضاري المتسارع الذي يؤدي إلي إفراز انحر افات

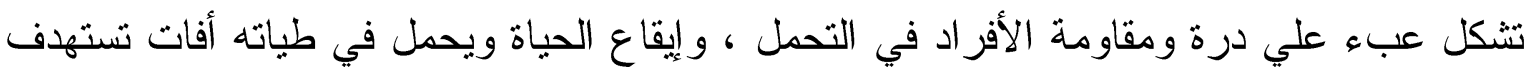

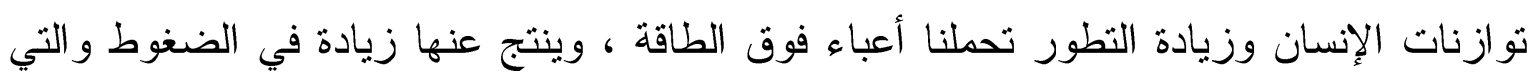




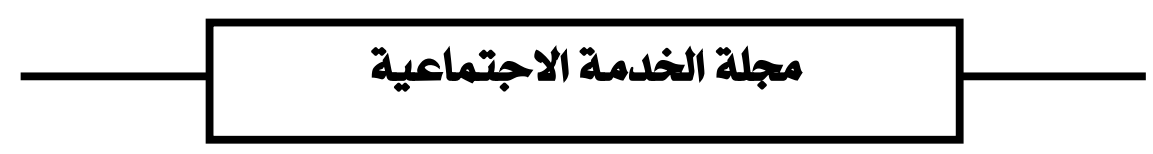

تهدد التوازنات و علي قدر نجاح الإنسان المعاصر في استيعاب النمو المنسار ع لمنطلبات الحضارة

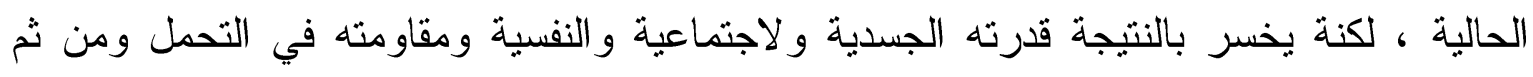

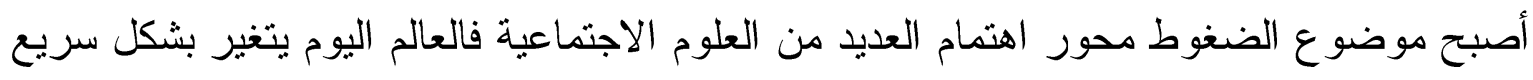

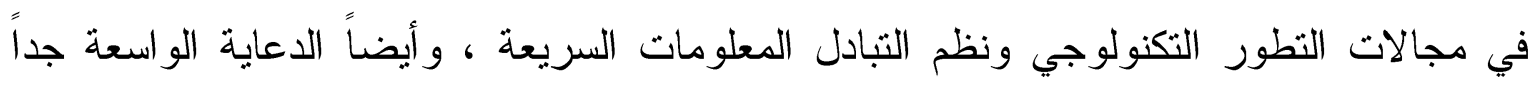

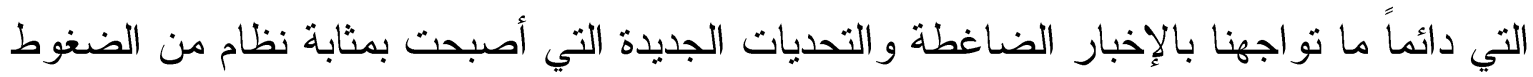

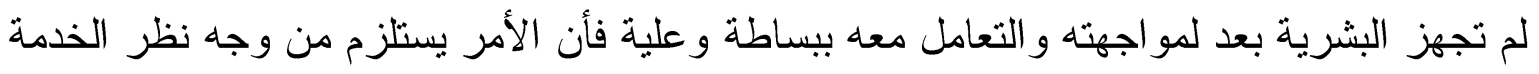

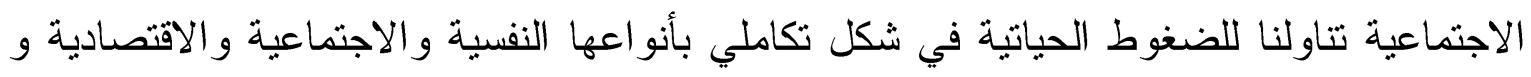

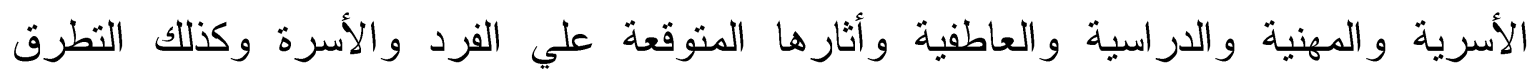

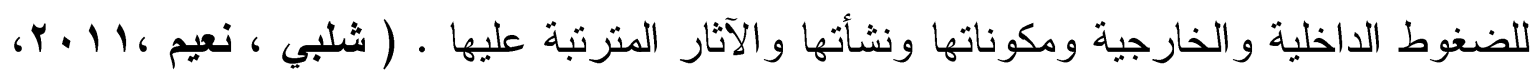

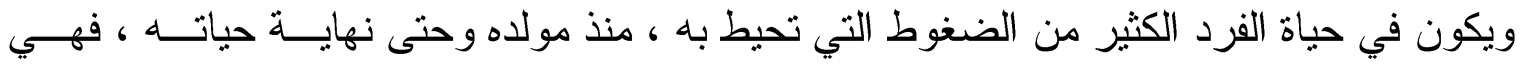

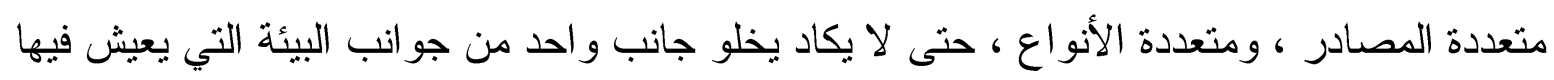

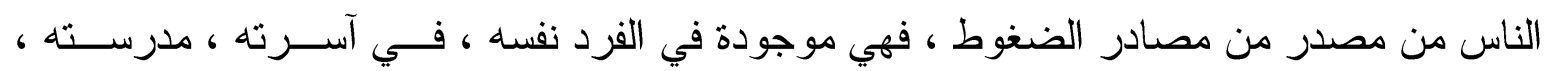

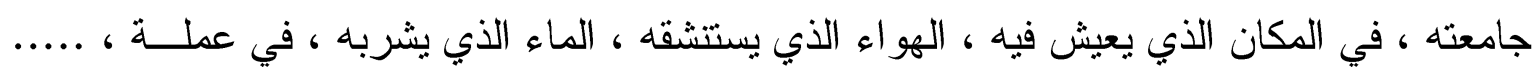

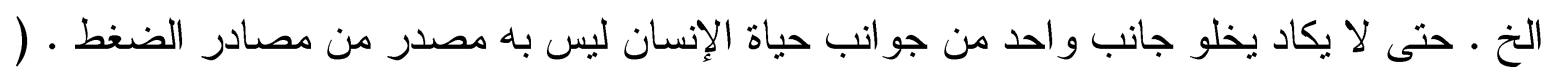

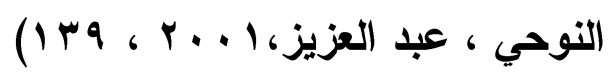

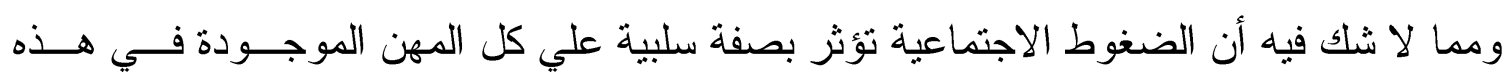

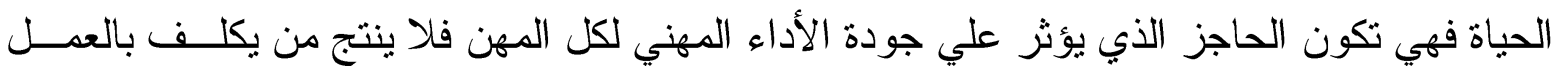

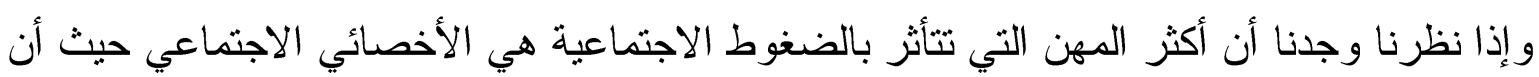

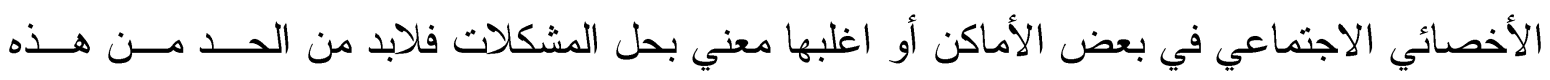

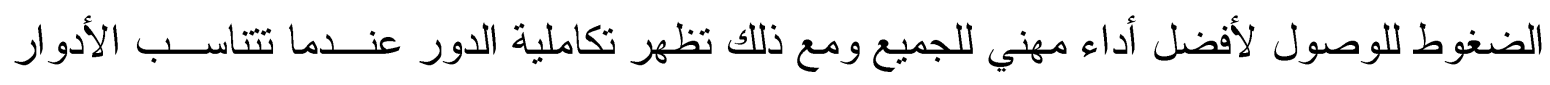

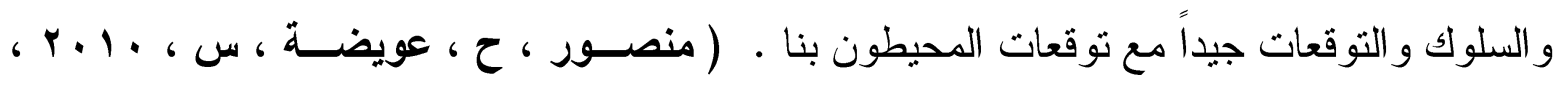

ويعد الأداء المهني للأخصائيين الاجتماعيين هو الشكل النهائي لكافة ممارساته في المو اقف المهنيـــة

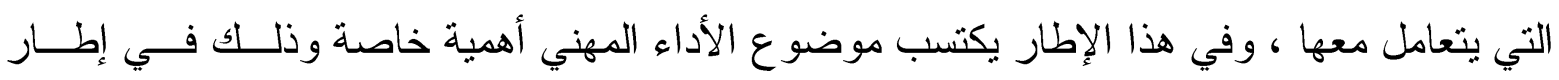

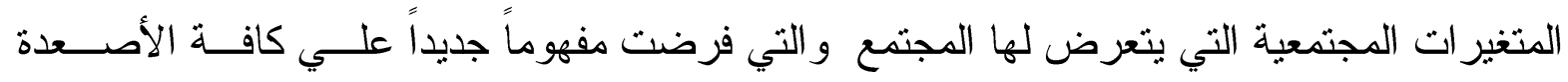

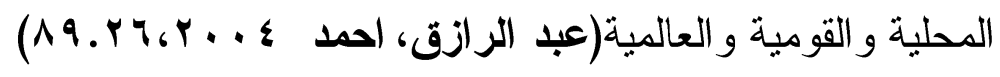




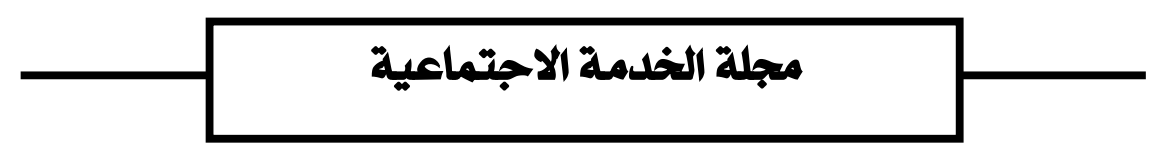

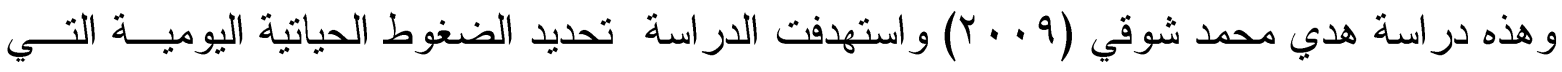
يتعرض لها الو الدين و انعكاساتها السلبية على الأبناء، تحديد ما هي أساليب التنشئة الغير سوية التي يستخدمها الو الدين مع الأبناء و انعكاساتها السلبية عليهم ، تحديد جوانب العلاقة بين الضغوط الحياتية

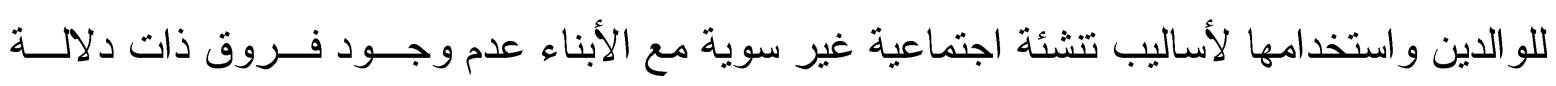

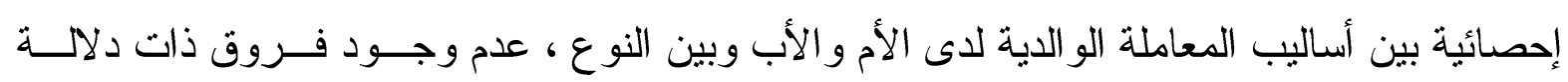
إحصائية بين الضغوط المتعلقة بخصائص الطفل بين الأب والأم وهى ( التو افقية - ثقبليـــه الو الــدين للطفل - كثرة الإلحاح - الثقلب المزاجي - النشتت - تدعيم الطفل للو الدين). سلوي أحمد أبوريا هنية ( . . r ) واستهدفت الدراسة تحديد العوامل المرتبطة بالضغوط الاجتماعية التي تتعرض لها المرأة العاملة في المجال الصناعي وتحديدا في صناعة الغزل و النسيج، توضيح أنواع الضغوط الاجتماعية لدى المر أة العاملة في مجال صناعة الغزل والنسيج، بينت الدراسة أن هناك علاقة ايجابية دالة إحصائيا بين الضغوط الاجتماعية وصراع الأدوار للمر أة العاملة، أشارت الدر اسة إلى ضرورة التخفيف من حدة الضغوط الاجتماعية على المر أة العاملة من خلال التوعية الثقافية و الدينية و الإعلامية و العلمية على المستويات المختلفة.

دراسة ( NASW ^ N . . ) واستهدفت معرفة المخاوف الصحية ومشكلات قد تحدث بسبب الضغوط لكن قد تتنج من هذه الضغوط مخاوف ومشكلات صحية ، هذه الضغوط هي ظروف العمل

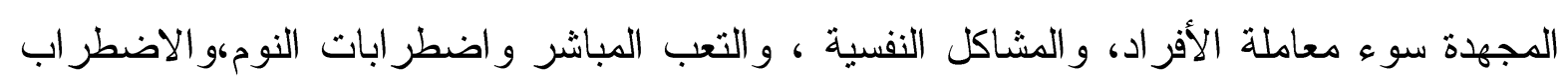
في العلاقات وذكر أن هناك مخاوف صحية متعلقة بالضغوط.

أما دراسة أحمد نصر ^ ^. . ع عن الاداء المهني واستهدفت هل تتوفر المهارات المهنية لدى الأخصائيين الاجتماعيين بمدارس التعليم العام في ضوء مفهوم إدارة الجودة الشاملة ، الكشف عن الفروق في المهار ات المهنية لاى الأخصائيين الاجنماعيين بحسب الجنس، الكشف عن الفروق في المهار ات المهنية لاى الأخصائيين الاجتماعيين بحسب الخبرة، الكثف عن الفروق في المهارات المهنية لدى الأخصائين الاجتماعيين بحسب العمر ووجد فروق ذات دلاية إحصائية بين كل المتغير ات.

در اسة سوكم شيلي (2008 Schuurman, Shelley D)و استهدف الدر اسة أن تصف بدقة الأداء المهني المتخصص لمهمة معقدة قدرة الفرد على "تنفيذ" يتطلب تطبيق المعرفة المكتسبة وهي العملية التي تثأثر بالخصائص الشخصية وقدر ات الفرد و الغرض من هذه الدر اسة الاستطلاعية هو در اسة ظاهرة الأداء المهني، على وجه التحديد، من حيث صلته الخصائص و القدرات الفردية التي تساهم 


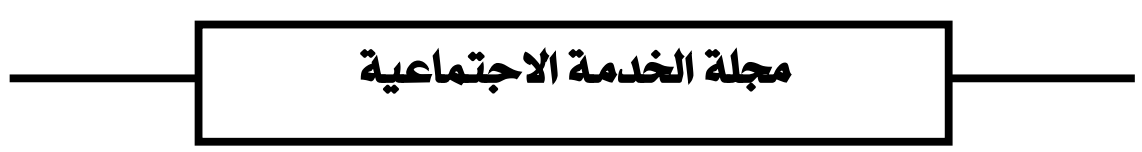

في الأداء المهني المتخصص في ممارسة الخدمة الاجتماعية باستخدام تتسيق إجراء المقابلات شبه المنظمة.

ثانيا : تستمد هذه الدراسة أهميتها من:

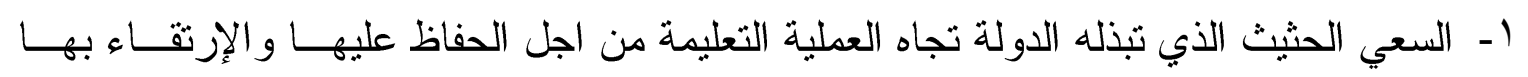
و الاهتمام بكافة العاملين داخل المؤسسة التعليمية ،ومن ضمنهم الأخصائيين الاجتماعين وما يحـيط بهم من مشكلات بشكل يستوجب ضرورة الاهتمام بدر استها مما يدفع العملية التعليمية إلى التقــدم و الارثقاء.

r- تتناول هذه الدر اسة مشكلة تعيق عمل الأخصائي الاجتماعي وتؤثر علي الأداء المهني له داخل مدارس التعليم الفني بشكل قد يفيد في تفعيل أدائه لدوره داخل المؤسسة التعليمية.

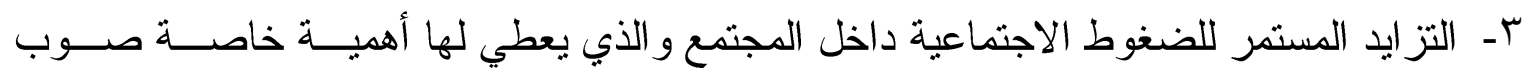
الاهتمام بدر استها في الوقت الحالي وذلك كمحاولة للتغلب عليها أو التخفيف من حدتها.

عـ يعد الأخصائي الاجتماعي احد محاور العملية التعليمية مما جعل الاهتمام به اهتمــام بالعمليـة التعليمية ومن فيها حيث يكون دورة فعال ونشط داخل المدرسة لذا كان من المحتم الوصــول إلـي حل كل العقبات التي تقف في طريقة . هـ إن تفسير الضغوط الاجتماعية وتحليل أسبابها قد يكون له نفعاً كبير اً في مساعدة الأخصـائيين الاجتماعيين في المؤسسة التعليمية للوصول إلي أفضل الحلول للتعامل معها . ثالثا : أهداف الار اسة: تسعي هذه الاراسة إلي تحقيق الهدف الرئيسي التالي: ا- التعرف علي الضغوط الاجتماعية و علاقتها بــالأداء المهنــي للأخصــائيين الاجتمـــاعيين العاملين بمدارس التعليم الفني .

وينبثق من هذا التهف الأهداف الفرعية الآتية:

أـ تحديد الضغوط الشخصية التي يتعرض لها الأخصائي الاجتماعي في بمــدارس التعلـيم الفنـي

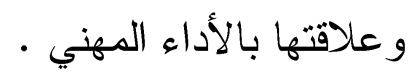

بـتحديد الضغوط المهنية و علاقتها بالأداء المهني للأخصائيين الاجتماعيين داخل مدارس التعلــيم الفني. 


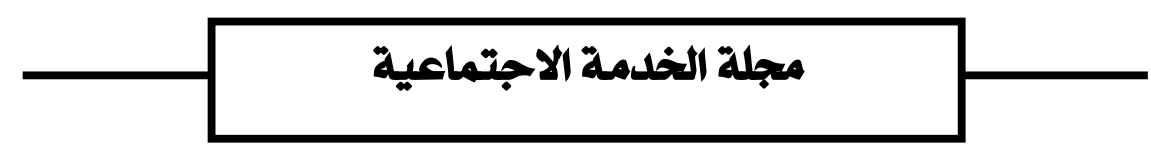

رابعاً : مفاهيم الار اسة : -

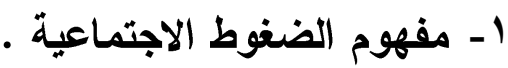

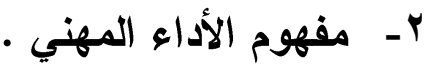

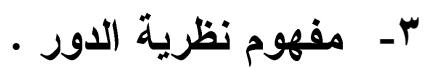

أولاً: مفهوم الضغوط الاجتماعية :

اما هانز سالي Hans Sale فقد عرفت الضغط علي أنة : على أنها استجابة غير محددة من الجسم

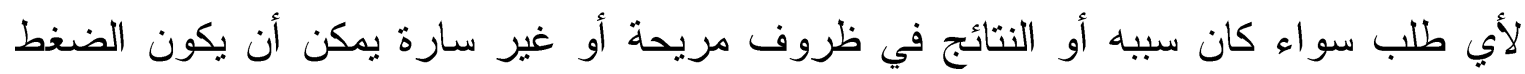

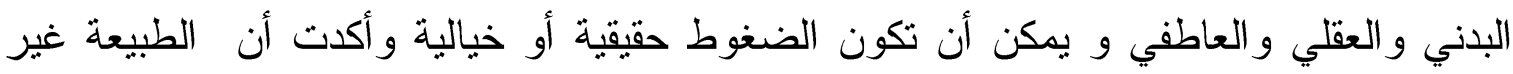

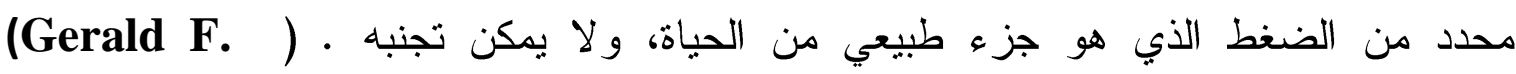

\section{Lackey,2005, p3}

وتعرف الضغوط علي أنها عو امل خارجية ضاغطة علي الفرد ، سواء بكليته أو جزء منه ، وبدرجة

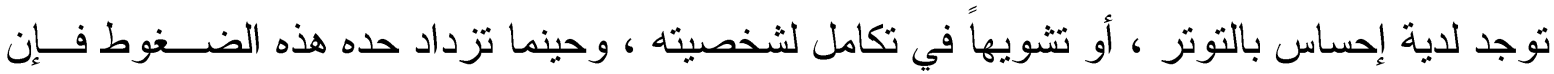

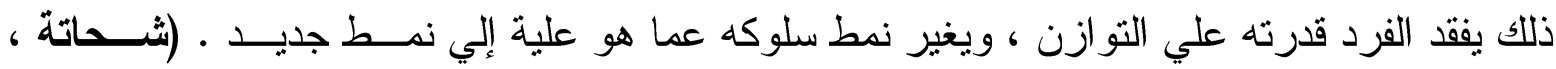

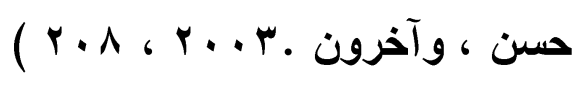

وتعرف الضغوط علي أنها : بأنها الحالة التي يدركها الكائن الذي يتعرض لأحداث أو ظروف معينـــة

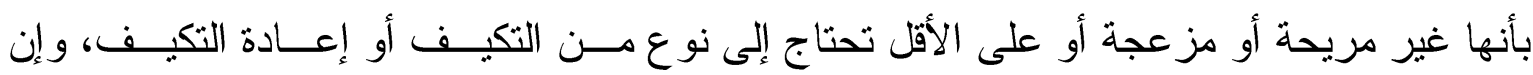

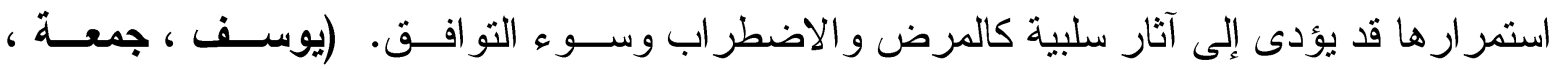
$(1 \mu, r \cdot V$

كما تعرف بأنها " تلك الظروف المرتبطة بالضغط ، وبالتوتز و الثدة الناتجة عن المنطلبــات أو

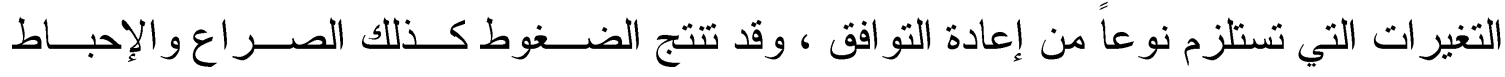

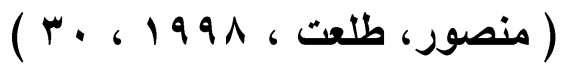

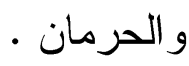
كما تعرف بأنها " القوي و المؤثزات المرتبطة بالتغير ات المصاحبة لأحداث الحيــاة ، وتـــؤدي

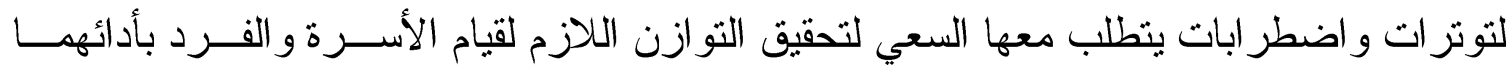

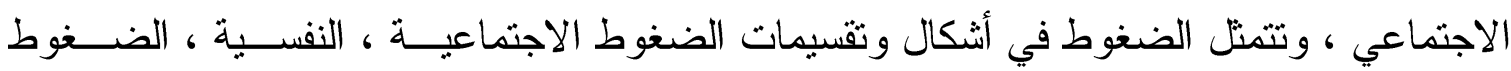

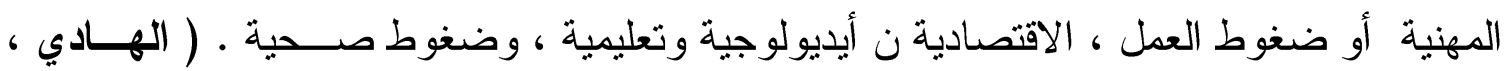




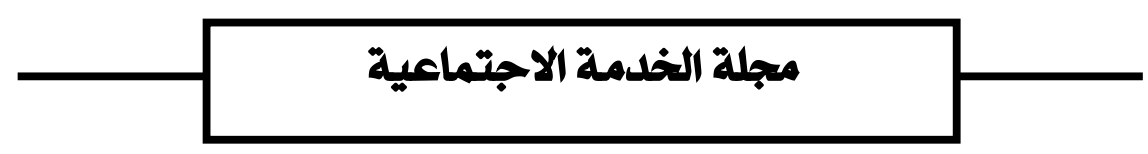

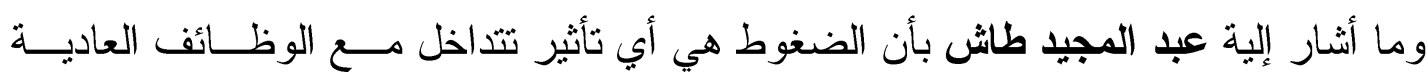

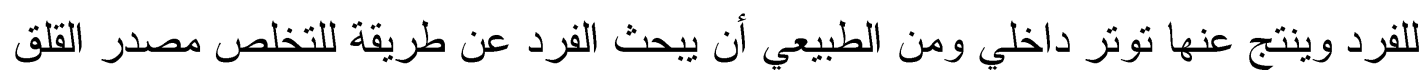

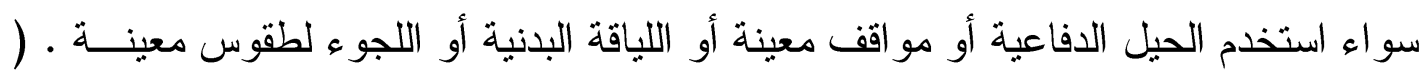

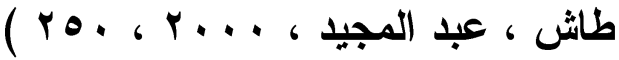

\section{وتعرف الضغوط الاجتماعية علي أنها :}

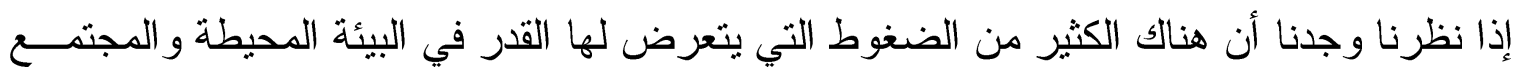

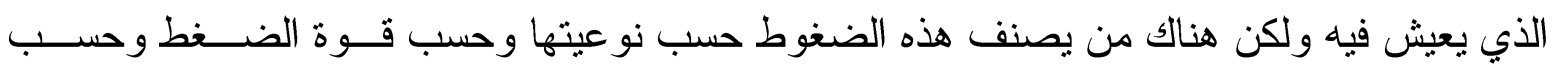

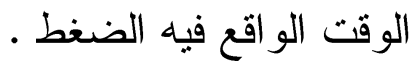
ثانياً: مفهوم الأداء المهني:

بداية ينظر للأداء لغوياً علي أنة " أداء الثيء أو القيام به أو انجازه " ( الوجيز ،99191، ، 1)

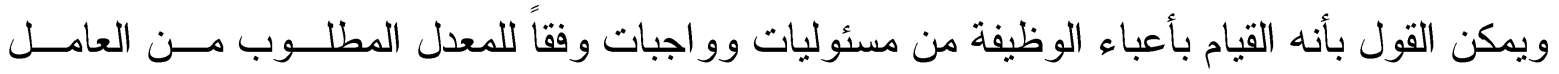

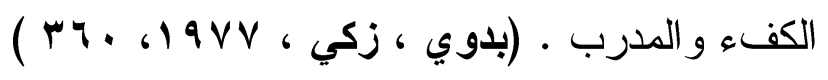

وجاء في المعجم المصطلحات التربوية انه انجاز يتم باستخدام الفرد لإمكاناته الجسمية أو العقلية أو أو الوات

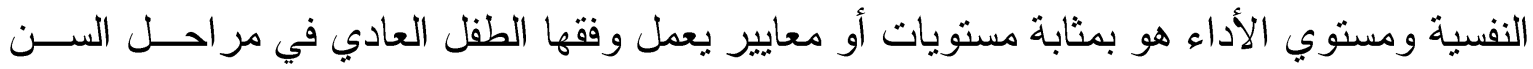

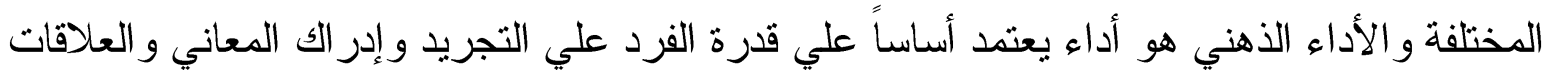

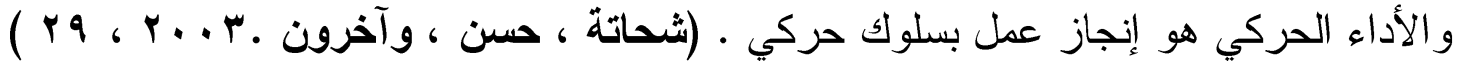

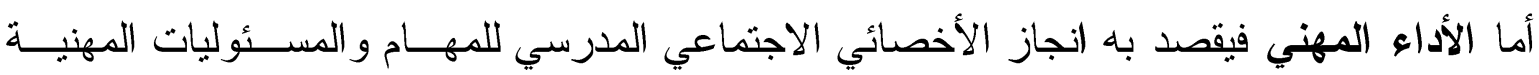

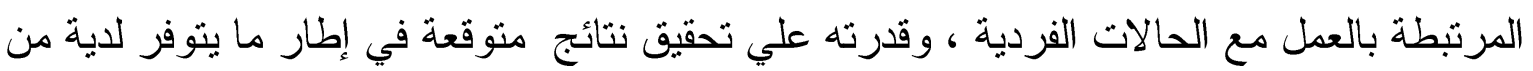

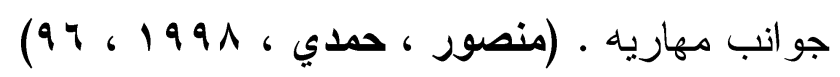
وقام سمير منصور بتعريف الأداء المهني للأخصائي الاجتمــاعي علــي أنـــة قـدرة الأخصــائي

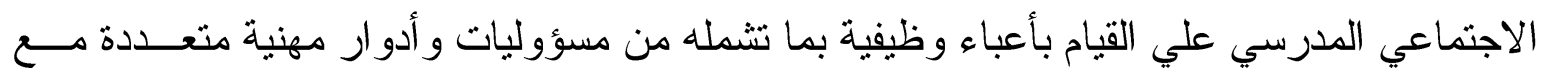

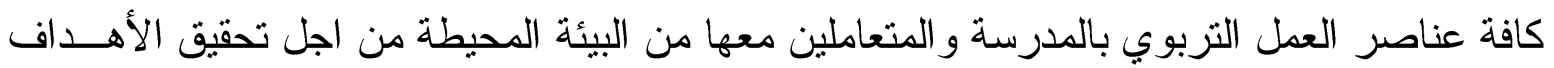

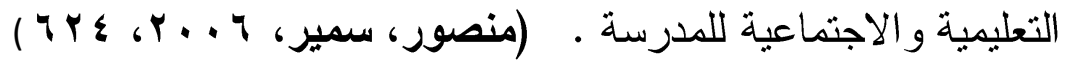
ومن ثم فيمكن أن نعرف الأداء المهني أنها انجاز العمل المنوط بالأخصائي الاجتماعي في الوقــــ

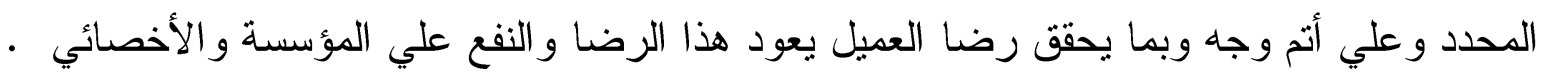

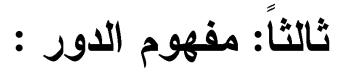




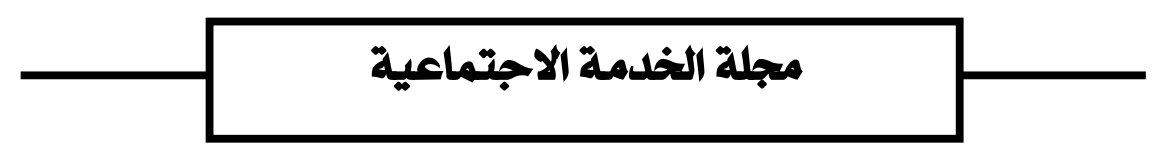

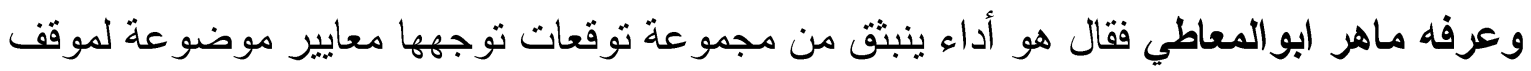

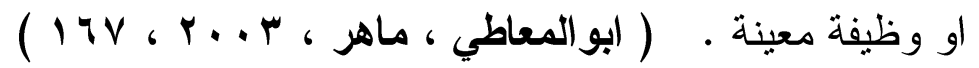
وقامت سامية الساعاتي بنعرف الدور بأنه"هو قطاع من النسق التوجيهي الكلي للفرد الفاعل وهــو

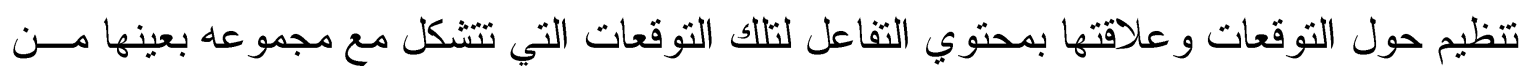

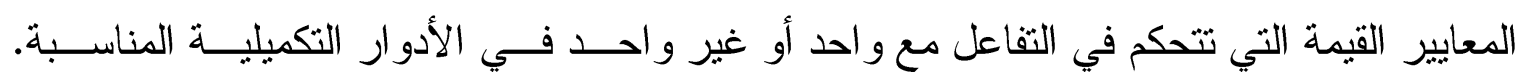

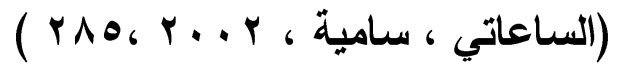

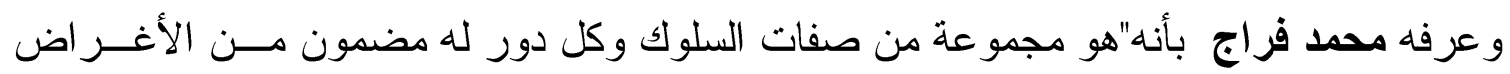

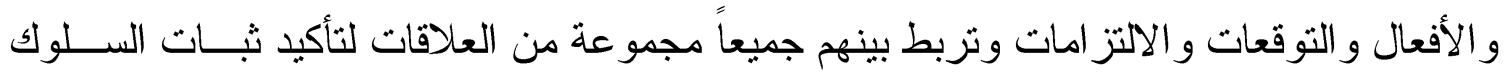

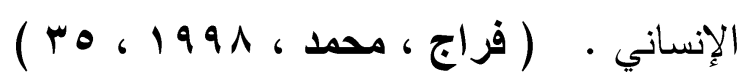

أما محمد الاسوقي فعرفه الدور بأنة مجموعة أفعال يقوم بها الفرد نتيجة موقف معـين أو بمعنـي

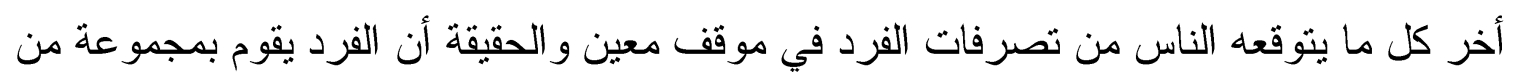

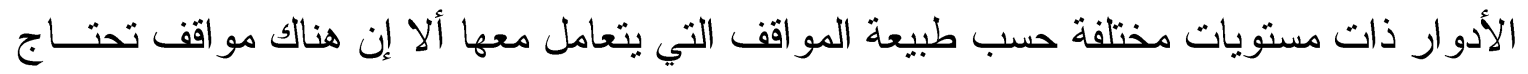

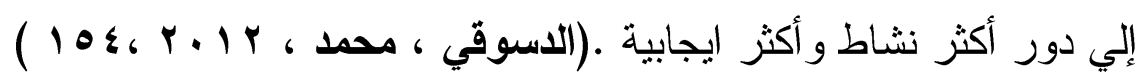
ويمكن القول بأن تعريف الدور إجرائياً هو: 1- الدور الفعلي الذي يقوم به الأخصائي الاجتماعي داخل المعهد. ץ- الدور هو الالتزام بالخطط المعدة من قبل رعاية الطلاب. r- انجاز الخطط في الوقت المحدد بالدور المطلوب لكل مهمة. ع - السعي للنتو اصل مع المؤسسات المحيطة. 0- أدار اك أن هناك مسئولية كبيرة علي عاتقة.

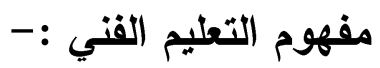

ذللك النوع من التعليم الذي يهدف الي إكساب الفرد قدرا من الثقافة والمعلومات الفنية و المهارات العملية التي تمكنه من إتقان أداء عملة ،وتتفيذه علي الوجة الاكمل وهذا النوع من التعليم تتضمن خطة الدراسية المواد العامة و الفنية و النطبيق العملي .(وزارة التربية و التعليم موقع) خامساً: الموجهات النظرية للار اسة :- 


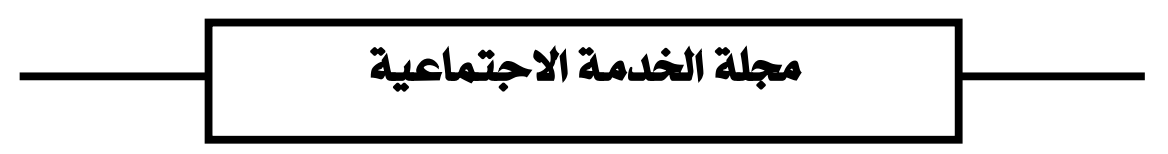

مما لا شك فيه أن الأخصائي الاجتماعي المدرسي يقوم بدور فعال داخل المدرسة وفي العديد مــن

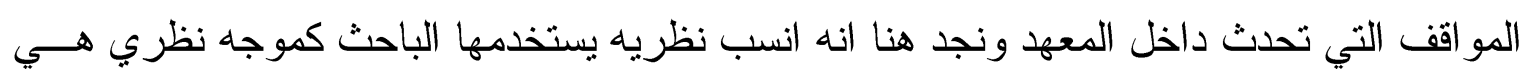

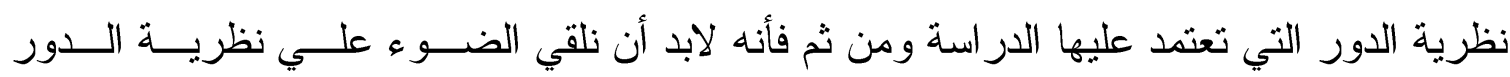

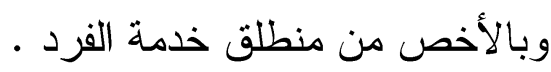

نظرية الدور :

أن الدور الاجتماعي يعد مفهوماً نافعاً لفهم العلاقات الثخصية التي يهنم بها الأخصائيون

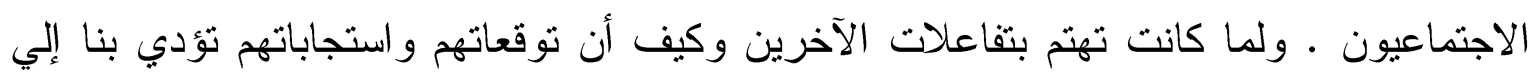

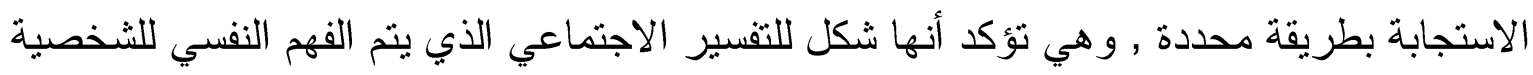

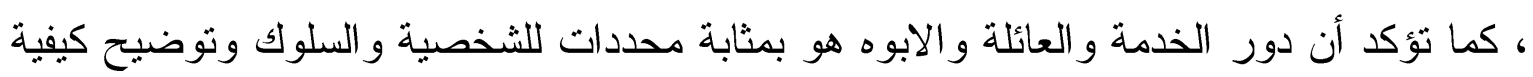

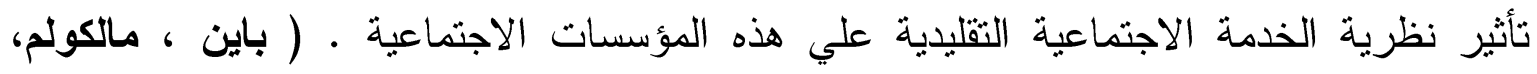
$(1 \Lambda \cdot 6 r \cdot 1$. الاجر اعات المنهجية للبحث:-

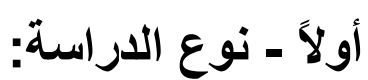

حيث تستهدف تحديد العلاقة بـين الضــغوط الاجتماعيــة و الأداء المهنــي للأخصــائيين الاجتماعيين بمدارس التعليم الفني .

تتنمي الدر اسة الحالية إلى نمط الدر اسات الوصفية باعتبار ها من أنسب الدر اسات ملائمــة لموضوع الدر اسة.

\section{ثانيا: المنهج المستخدم :}

تعتمد هذه الدراسة علي منهج المسح الاجتماعي بالعينة وهذا باعتباره من المنــاهج المناسـبة

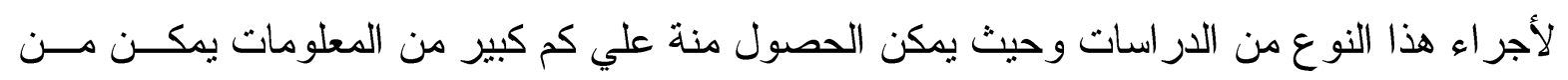

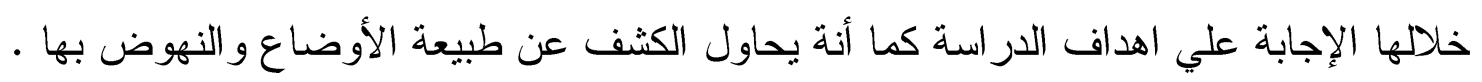
ثالثاً:الأدوات المستخدمة: - n استمارة استبيان للأخصائيين الاجتماعيين العاملين بمدارس التعليم الفني .

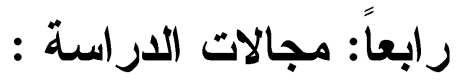
1- المجال البشري : 


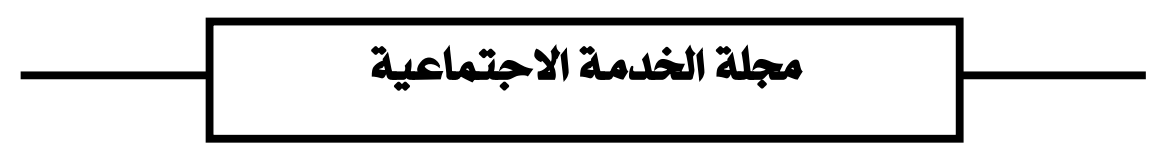

سوف نطبق هذه الدر اسة علي عينة عشو ائية منتظمة لجميع الأخصائيين الاجتماعيين العاملين في

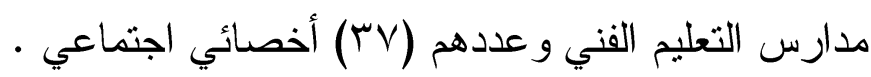

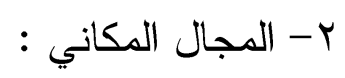
مدارس التعليم الفني بسو هاج : مالج

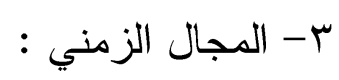

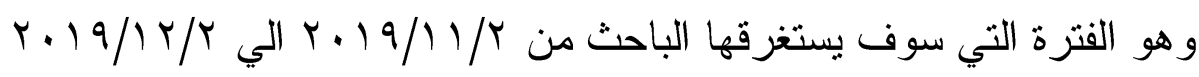

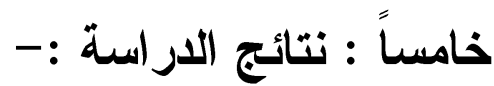
توضيح ن = V :هي عينة عشو ائية منتظمة من الأخصائيين الاجتماعيين في مدارس التعليم الفني

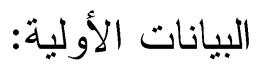

$$
\text { جدول رقم (1) يوضح توزيع الأخصائيين الاجتماعيين وفق للنوع ن= }
$$

\begin{tabular}{|c|c|c|c|}
\hline النسبة المئوية & التكر ار & الهوح & ? \\
\hline$\% \vee \cdot, r$ & Y & ذكر & 1 \\
\hline$\%$ \%, , & 11 & انثي & $r$ \\
\hline$\% 1 \ldots$ & rv & \multicolumn{2}{|c|}{ المجموع } \\
\hline
\end{tabular}

بإستقراء بيانات الجدول السابق يتضح أن النسبة الأعلى من الأخصائيين الاجتماعيين العاملين في

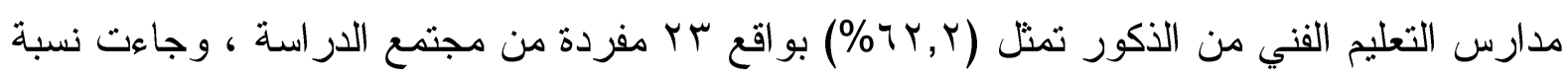

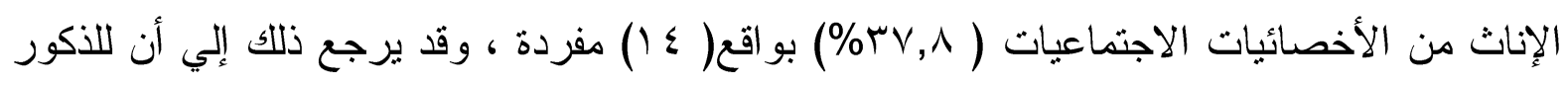

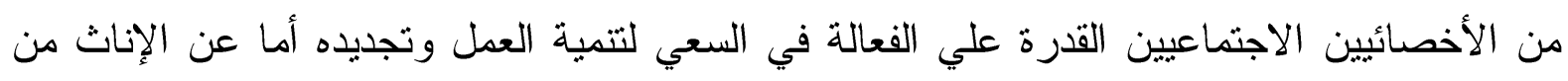

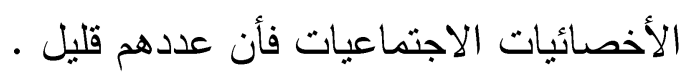




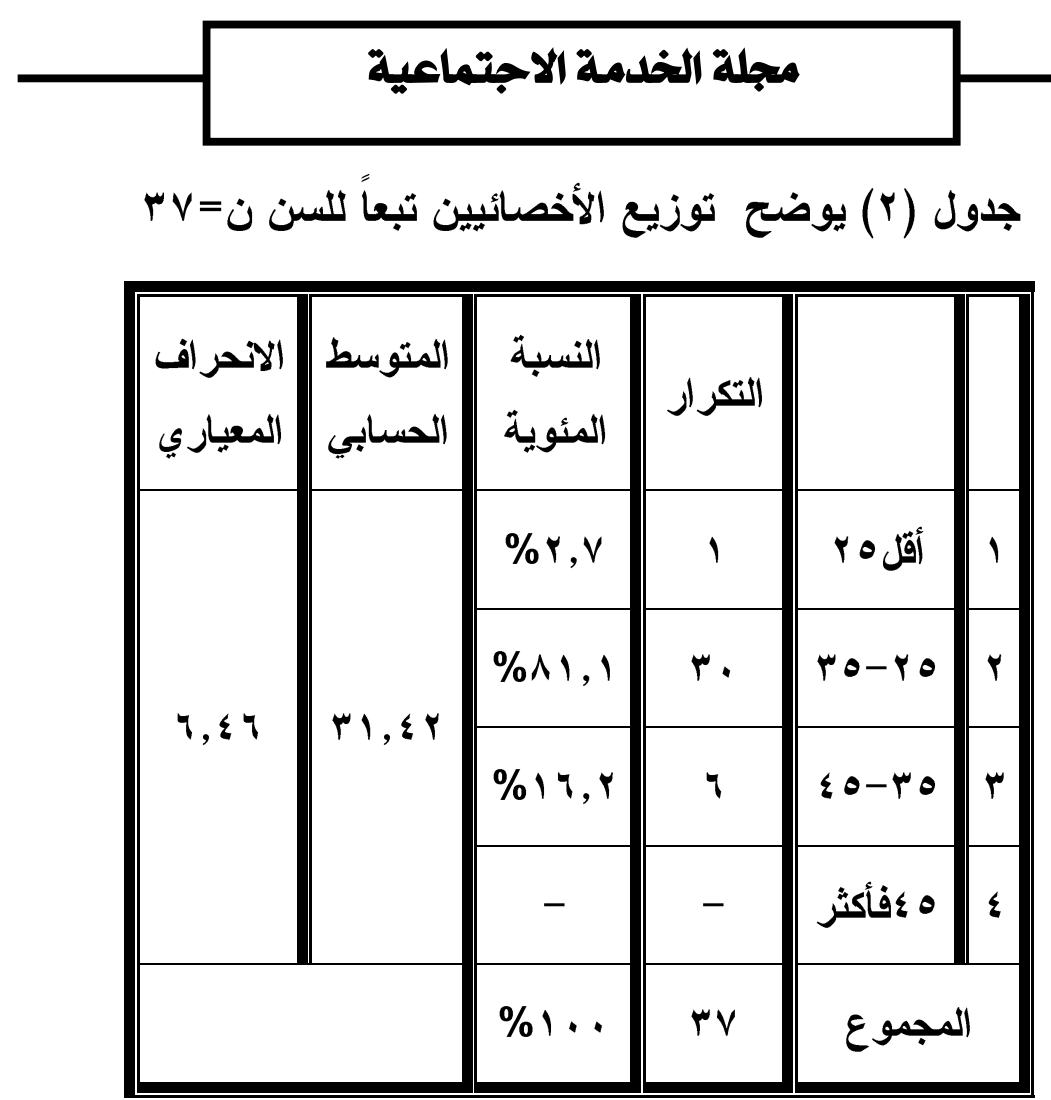

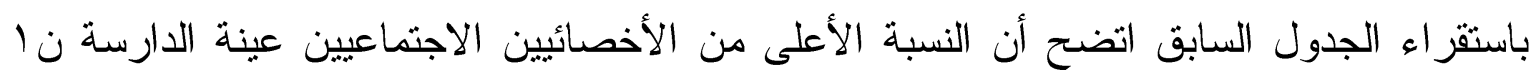

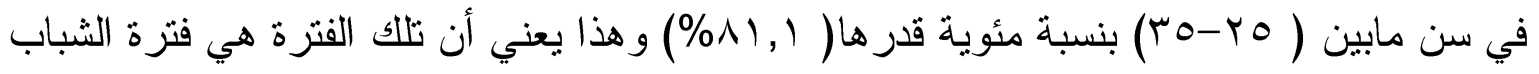

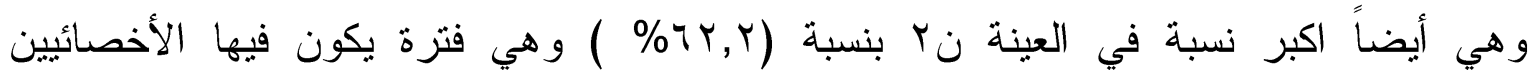

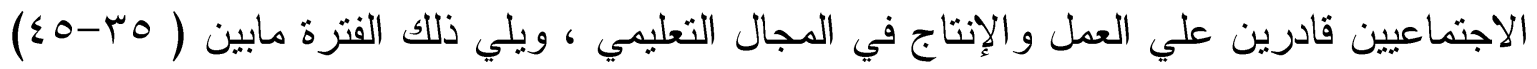

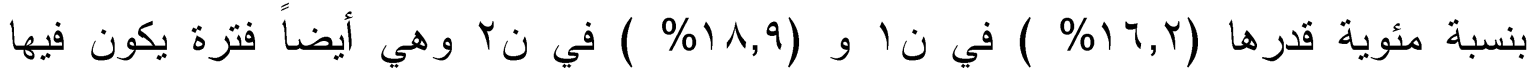

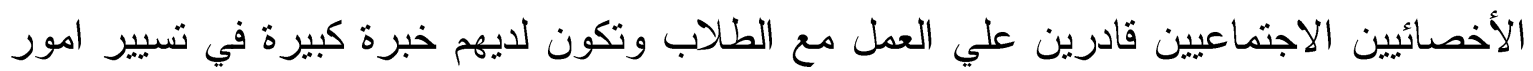

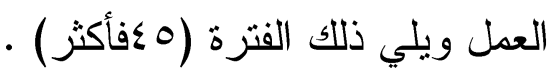

$$
\text { جدول(r) يوضح المؤهل الدراسي ن=rV }
$$

\begin{tabular}{|c|c|c|c|}
\hline النسبة المئوية & 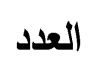 & المؤهل الدراسي & م \\
\hline - & - & دبلوم خدمة اجتماعية & 1 \\
\hline$\%$ \% , ० & ro & بكالوريوس خذمة اجتماعية & $r$ \\
\hline$\% \diamond, \varepsilon$ & r & ليسانس آداب اجتماع & $r$ \\
\hline$\%$ rv, 1 & 1. & در اسات عليا & $\varepsilon$ \\
\hline$\% 1 \ldots$ & $r v$ & المجموع & \\
\hline
\end{tabular}




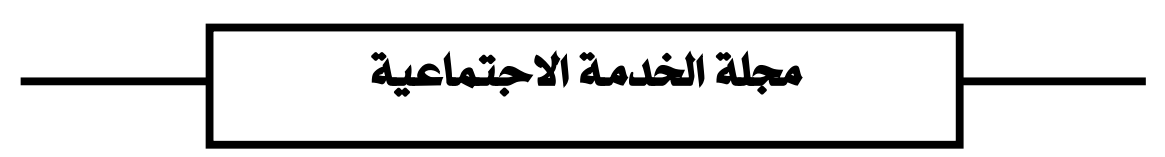

باستقراء الجدول السابق والذي يشير إلي المؤهل ألدارسي للأخصائيين الاجتماعيين ان النسبة

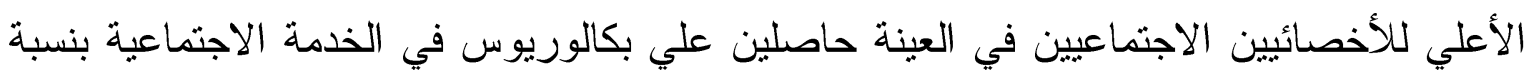

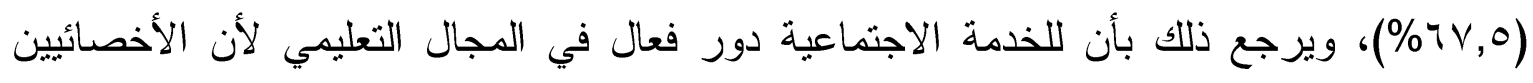

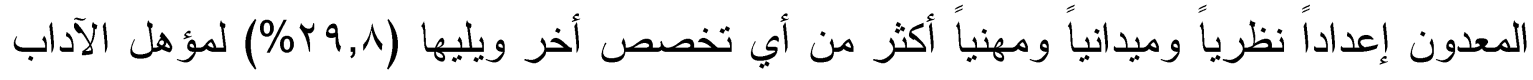

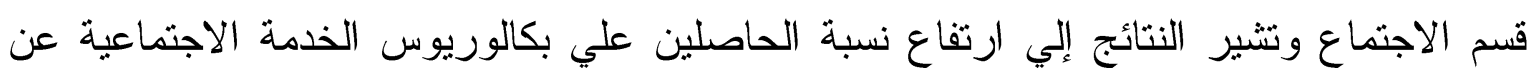

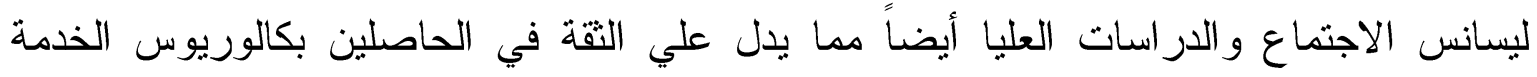
الاجتماعية لما يتمتعون به من إعداد جيداً في المجال التعليمي.

$$
\text { جدول(ع يوضح مدة عمل الأخصائيين الاجتماعيين بالمعاهد ن }
$$

\begin{tabular}{|c|c|c|c|c|c|}
\hline الالمعراف & الحسابي & المئوية & التكرار & الخبرة & \\
\hline \multirow{4}{*}{$r \cdot, l v$} & \multirow{4}{*}{$\Lambda, \vee 1$} & $\% 0$ & $r$ & أقل من & 1 \\
\hline & & $\% \vee r$ & rV & $1 .-0$ & $r$ \\
\hline & & $\% 1 \leq$ & 0 & $10-1$ & $r$ \\
\hline & & $\% \wedge$ & $r$ & |ه افأكثر & $\varepsilon$ \\
\hline & & $\% 1 \ldots$ & rv & لمجموع & \\
\hline
\end{tabular}

يتضح من بيانات الجدول السابق الذي يوضح لنا أن النسبة الأعلى من الأخصائيين الاجتماعيين في

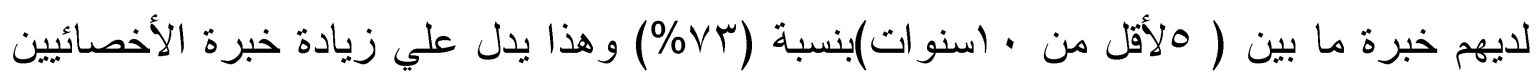

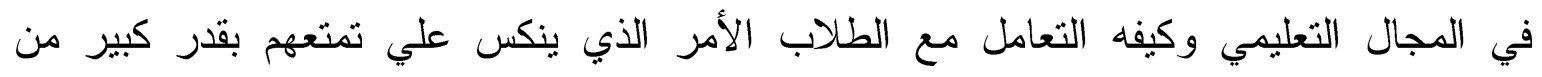
المهار ات و الخبر ات في المجال المدرسي و التعامل الجيد مع الطلاب في مدارس التعليم الفني الذي لئي

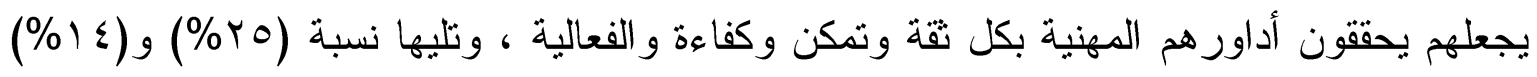

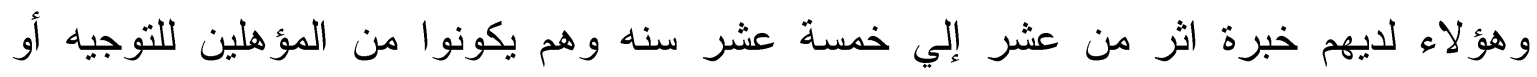

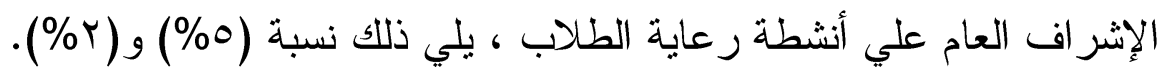




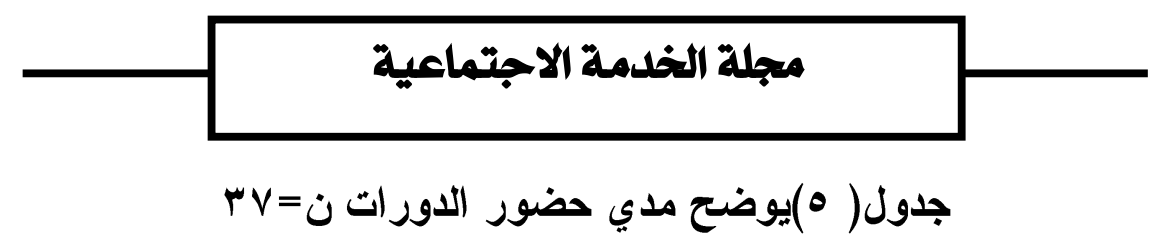

\begin{tabular}{|c|c|c|c|}
\hline النسبة المئوية & المطبقة للجودة & حضور الدورات & م م \\
\hline$\% \wedge r, \wedge$ & m & نعم & 1 \\
\hline$\% 17, r$ & 7 & $\gamma$ & $r$ \\
\hline$\% 1 \ldots$ & $r v$ & & المج \\
\hline
\end{tabular}

تشير بيانات الجدول السابق إلي أن نسبة (^,^^\%) في العينة قد حصلوا علي دورات تدريبية ،

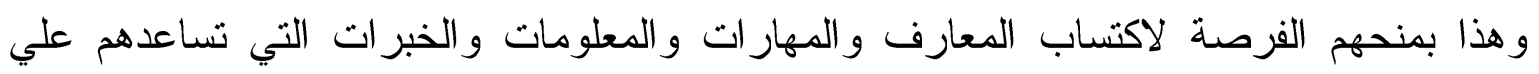

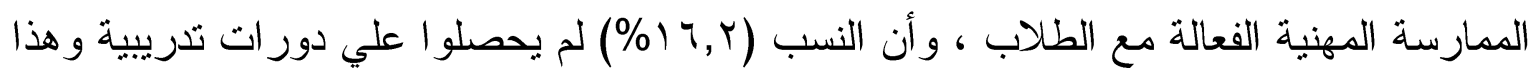

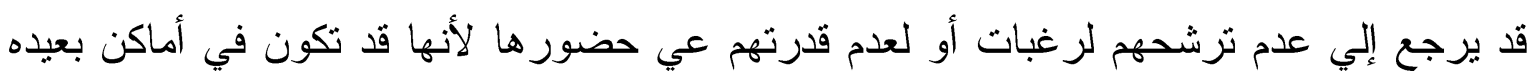

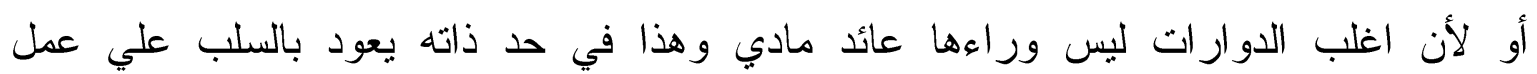

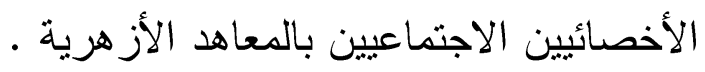

$$
\text { جدول( T) يوضح الرغبة في اخذ الدورات ن= }
$$

\begin{tabular}{|c|c|c|c|}
\hline النسبة المئوية & دورات & & $p$ \\
\hline$\% 1 \ldots$ & $r v$ & نعم & 1 \\
\hline - & · & ע & $r$ \\
\hline$\% 1 \ldots$ & $r v$ & \multicolumn{2}{|c|}{ |المجموع } \\
\hline
\end{tabular}

يتضح من الجدول السابق أن هناك رغبة عند الأخصائيين الاجتماعيين الحاصلون علي دورات في مجال التخصص ونجد أن النسبة (...1\%) 


\section{مجلة الخدمة الاجتماعيةل}

جول يوضح (V)(أوجه استفادة الأخصائيين الاجتماعيين من الدورات التدريبية (I (r)

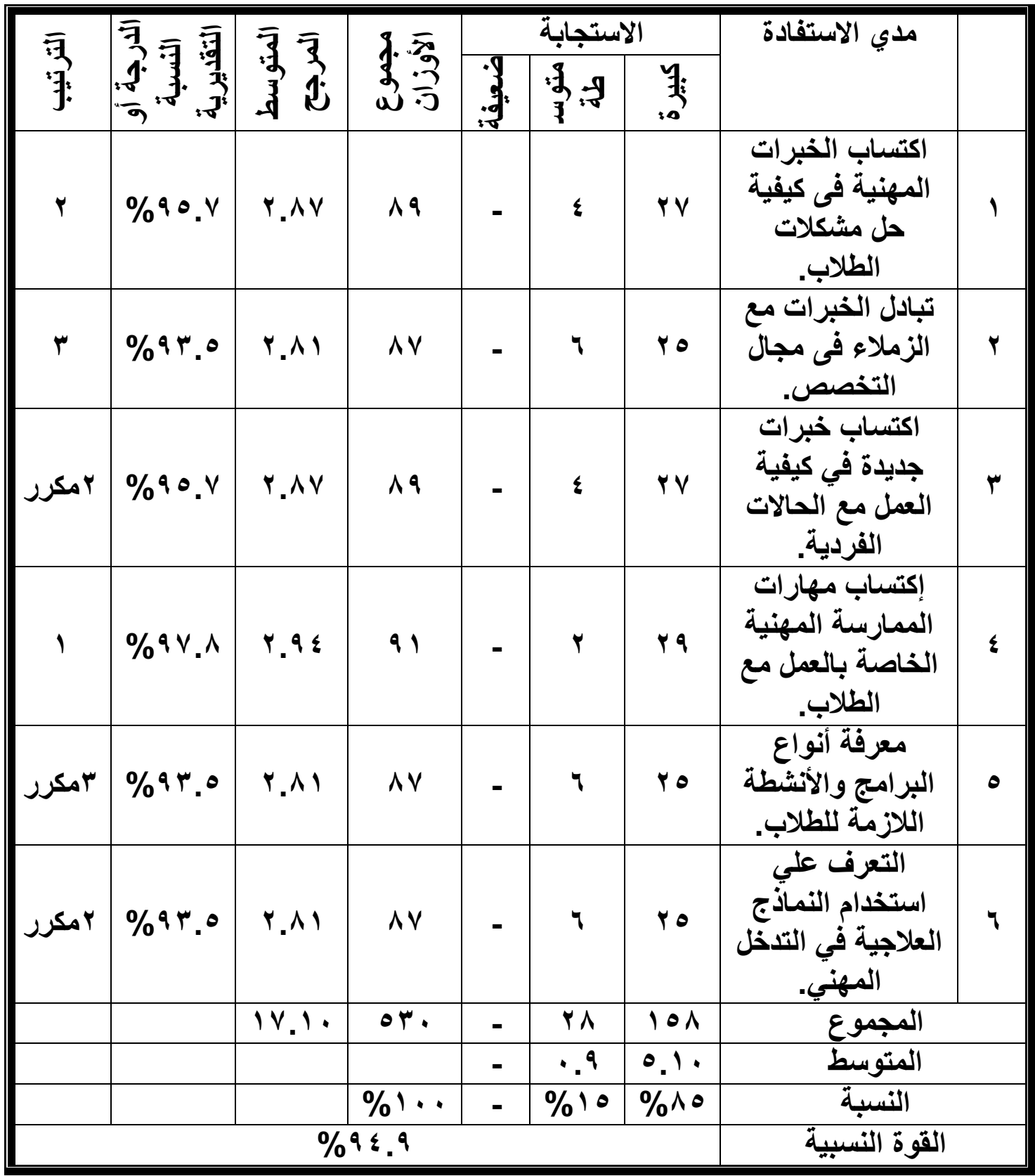

باستقر اء الجدول السابق نجد أن هناك العديد من النتائج التي توضح مدي الاستفادة من الدوارات التنريبية

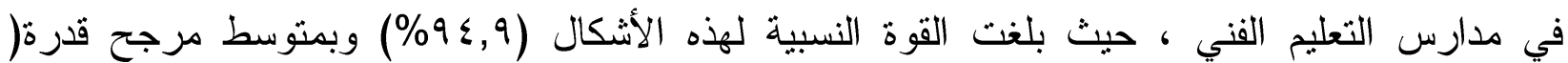

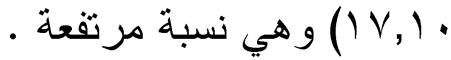




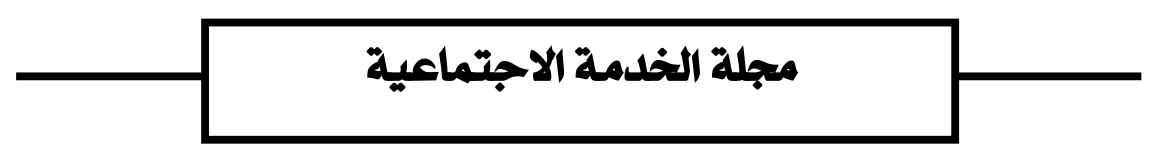

وتثير البيانات في الجدول السابق أن هناك بعض القصور في المحتوي التدريبي من ناحية

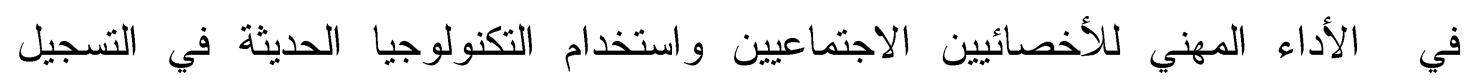

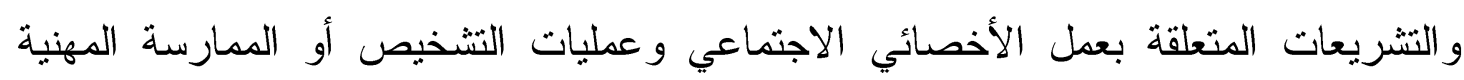

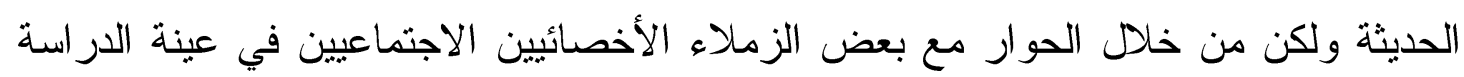

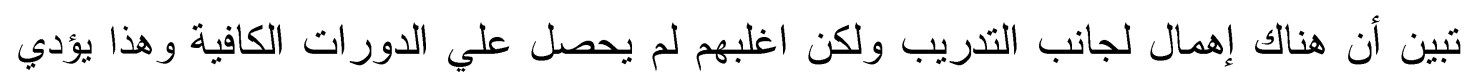

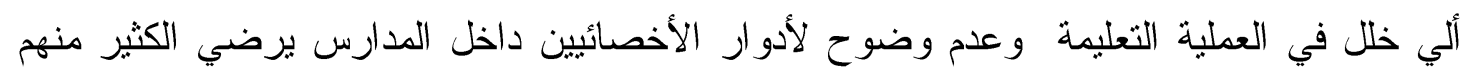

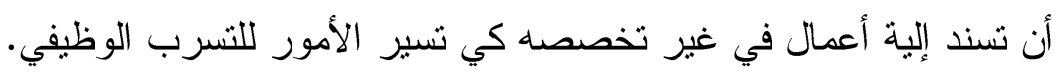

جدول( ^ )يوضح الدورات التي يرغب الأخصائيين الاجتماعيين في الحصول عليها ( ن= (rV

\begin{tabular}{|c|c|c|c|c|c|c|c|}
\hline \multicolumn{2}{|c|}{$\gamma$} & \multicolumn{2}{|c|}{ إلى حـ } & \multicolumn{2}{|c|}{ نعم } & \multirow{2}{*}{ اسم الدورة } & \\
\hline 予. & $\overline{7}$ & 哥 & 7. & 雪 & $\overline{7}$ & & \\
\hline- & - & - & - & $\% 1 \ldots$ & $T V$ & دور ات فى مجال جودة الأداء المهني للأخصائي & 1 \\
\hline- & - & - & - & $\% 1 \ldots$ & $\mu v$ & دور في الأساليب التشخيصية الحديثة لمشكلات & $r$ \\
\hline- & - & - & - & $\% 1 \ldots$ & $r v$ & دور ات فى الأساليب العلاجية الحديثة في المجال & r \\
\hline- & - & - & - & $\% 1 \ldots$ & rV & دور ات فى مجال الإدارة الددرسية والتشريعات & $\varepsilon$ \\
\hline- & - & - & - & $\% 1 \ldots$ & TV & دور ات فى مجال التعامل مع المشكلات الفردية & 0 \\
\hline- & - & - & - & $\% 1 \ldots$ & $\mu v$ & دور ات في استخدام التكنولوجيا الحديثة في & 7 \\
\hline
\end{tabular}




\section{مجلة الخلمة الاجتماعيةص}

باستقراء الجدول السابق يتضح أن جميع الأخصائيين الاجتماعيين يرغبون في اخذ هذه

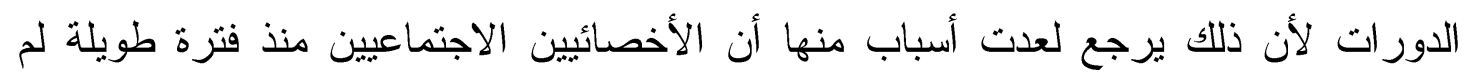

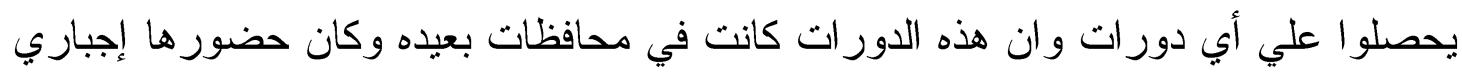

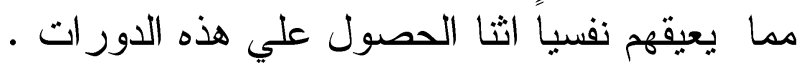
جدول رقم (9) يوضح الضغوط الثخصية ن = (TV) أولاً: الضغوط الاجتماعية: - أو

\begin{tabular}{|c|c|c|c|c|c|c|c|c|}
\hline \multirow[b]{2}{*}{ 哥: } & \multirow{2}{*}{ 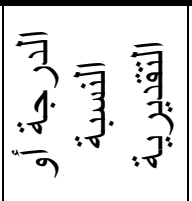 } & \multirow{2}{*}{ 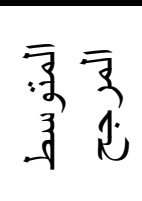 } & \multirow[b]{2}{*}{ 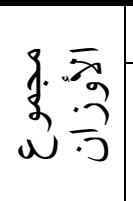 } & \multicolumn{3}{|c|}{ الاستجابة } & \multirow[t]{2}{*}{ العبارة } & \\
\hline & & & & 7 & $\bar{y}_{3}$ & $x$ & & \\
\hline 7 & 49.55 & 1.49 & 55 & 27 & 2 & 8 & أنشعر بضعف القدرة علي & 1 \\
\hline 1. & 33.33 & 1.00 & 37 & 37 & 0 & 0 & أثشعر بفقدان الثقة بالنفس & $r$ \\
\hline 1 & 100.00 & 3.00 & 111 & 0 & 0 & 37 & أنأتر بكثرة المشكلات التي لها & r \\
\hline V & 48.65 & 1.46 & 54 & 24 & 9 & 4 & 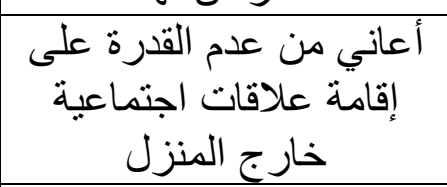 & $\varepsilon$ \\
\hline$r$ & 83.78 & 2.51 & 93 & 8 & 2 & 27 & أعاني من كثرة المشكلات الماتية المثاتية & 0 \\
\hline$\wedge$ & 38.74 & 1.16 & 43 & 31 & 6 & 0 & بعض للالفضر الخلافات من الجيران & 7 \\
\hline 9 & 35.14 & 1.05 & 39 & 35 & 2 & 0 & لاي مشكلات فى محل & V \\
\hline 0 & 75.68 & 2.27 & 84 & 11 & 5 & 21 & 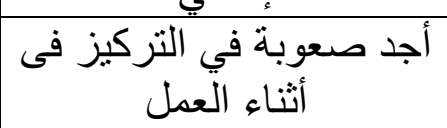 & $\wedge$ \\
\hline$\varepsilon$ & 78.38 & 2.35 & 87 & 9 & 6 & 22 & أصبحت سريع الغضب & 9 \\
\hline \multirow[t]{4}{*}{$r$} & 92.79 & 2.78 & 103 & 0 & 8 & 29 & أتأتثر بالخلافات الأسرية & 1. \\
\hline & & 19.08 & 706 & 182 & 40 & 148 & المجموع & \\
\hline & & & & 18.2 & 4 & 14.8 & المتوسط & \\
\hline & & & 100 & 49.19 & 10.81 & 40 & النسبة & \\
\hline \multicolumn{7}{|c|}{ \% \% } & القوة النسبية & \\
\hline
\end{tabular}

باستقر اء بيانات الجدول السابق عند قياس الضغوط الشخصية للأخصائيين الاجنماعيين بلغت الته

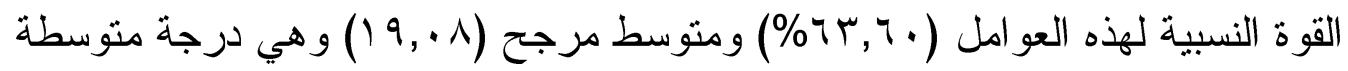
جدول (· ) يوضح الضغوط المهنية ن=rV 


\begin{tabular}{|c|c|c|c|c|c|c|c|c|}
\hline \multicolumn{7}{|c|}{ الغير مطبقة } & \multirow[b]{3}{*}{ مدى الاستفادة } & \multirow[t]{3}{*}{ م } \\
\hline$\overline{7}$ & Э & $\overline{7} 3$ & g. $\overline{\operatorname{sg}}$ & \multicolumn{3}{|c|}{ الاستجابة } & & \\
\hline 急: & 5. & & a & $x$ & $\overline{31}$ & 2 & & \\
\hline$\Lambda$ & 96.40 & 2.89 & 107 & 0 & 4 & 33 & أعاني من كثرة أعباء العمل & 1 \\
\hline 1 & 100.0 & 3.00 & 111 & 0 & 0 & 37 & 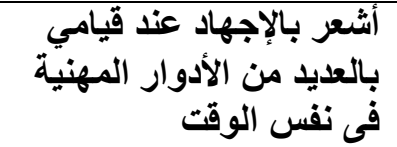 & $r$ \\
\hline r rكرנ & 100.0 & 3.00 & 111 & 0 & 0 & 37 & 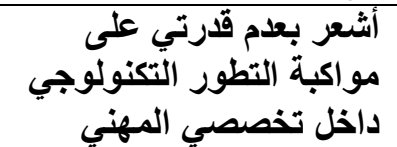 & $r$ \\
\hline 9 & 89.19 & 2.68 & 99 & 6 & 0 & 31 & 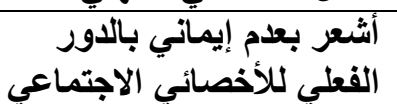 & $\varepsilon$ \\
\hline 1. & 81.08 & 2.43 & 90 & 7 & 7 & 23 & أشعر بـالاغتراب المهني & 0 \\
\hline آمكرر & 100.0 & 3.00 & 111 & 0 & 0 & 37 & أشعر بالدرمان من فرصية التشريبة & 9 \\
\hline Ir & 33.33 & 1.00 & 37 & 37 & 0 & 0 & بعض أنعرض للابس بالمعهة من قبل & $\mathrm{V}$ \\
\hline ع ع عرر & 100.0 & 3.00 & 111 & 0 & 0 & 37 & أوصاني من عدم واضح لدوري في & $\wedge$ \\
\hline مكرر & 100.0 & 3.00 & 111 & 0 & 0 & 37 & لالئحة في التموح والرغبة والتميز & 9 \\
\hline ' 1ككرر & 100.0 & 3.00 & 111 & 0 & 0 & 37 & أشعُ بفجوة بين الواقع & $1 \cdot$ \\
\hline Ir & 53.15 & 1.59 & 59 & 26 & 0 & 11 & أشعر بالسلبية اتجاه عملي & 11 \\
\hline 11 & 62.16 & 1.86 & 69 & 21 & 0 & 16 & فريق العقلم بالمعهر بعاون مع باقي & Ir \\
\hline \multirow[t]{4}{*}{ 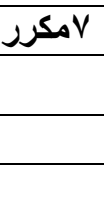 } & 33.33 & 1.00 & 37 & 37 & 0 & 0 & لا أهتم بحاجات الآخرين & ir \\
\hline & & 31.46 & 1164 & 134 & 11 & 336 & \multicolumn{2}{|c|}{ المجموع } \\
\hline & & & & 10.31 & 0.85 & 25.85 & \multicolumn{2}{|c|}{ المتوسط } \\
\hline & & & 100.00 & 27.86 & 2.29 & 69.85 & \multicolumn{2}{|l|}{ النسبة } \\
\hline \multicolumn{7}{|c|}{$\% \wedge \cdot, 77$} & \multicolumn{2}{|l|}{ القوة النسبية } \\
\hline
\end{tabular}

باستقر اء بيانات الجدول السابق عند قياس الضغوط المهنية للأخصائين جاءت القوة النسبية

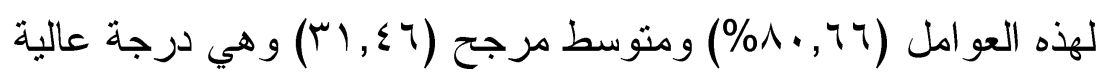




\begin{tabular}{|c|c|c|c|c|c|}
\hline & ف & متوسط المربعات & |درجة الحرية & مجموع المربعات & \\
\hline \multirow{3}{*}{ دالة } & $\varepsilon Y . \& Y$ & $1 \cdot 1.7 \leq$ & $r$ & $r \cdot r . r q$ & \multirow{3}{*}{ الضغوط الشخصية } \\
\hline & & r.rq & $r \varepsilon$ & $11 . \leqslant 0$ & \\
\hline & & & $r y$ & $r \wedge \varepsilon . \vee 0$ & \\
\hline \multirow{3}{*}{ دالة } & $r \wedge . \varepsilon q$ & $11 \leqslant .19$ & $r$ & YYq.VY & \multirow{3}{*}{ الضغوط المهنية } \\
\hline & & r.q1 & $r \varepsilon$ & $1 \cdot 1 . \leqslant 0$ & \\
\hline & & & $r q$ & rrI.1A & \\
\hline
\end{tabular}

يلاحظ من الجدول السابق أن هناك فروقا ذات دلالة بين متوسطات مؤهلات

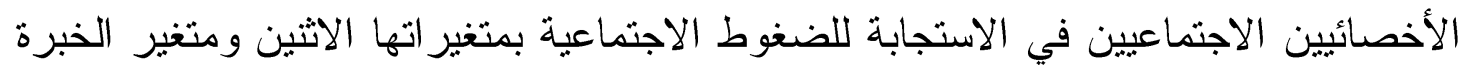

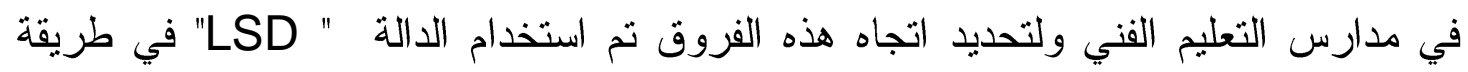

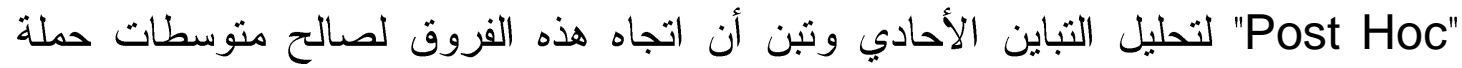

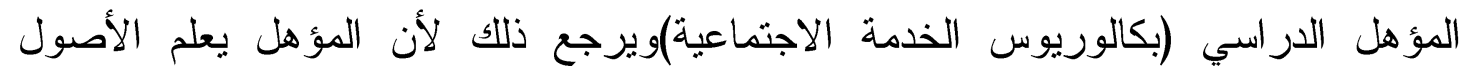

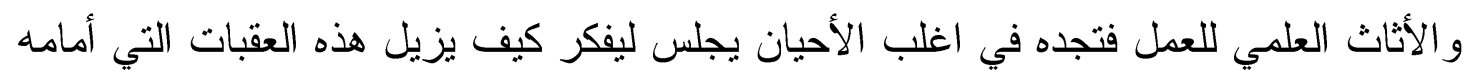

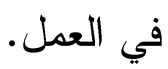

\section{توصيات الاراسة:}

ا. إجر اء در اسات مماتلة تتتاول مشكلة الضغوط الاجتماعية بصورة تكمل باقي الضغوط.

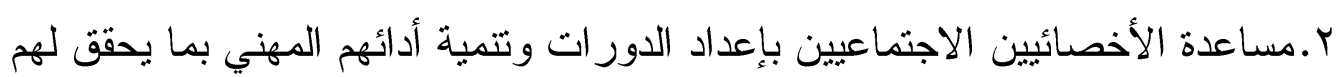
الرضي الوظيفي. r.توجيه الأخصائيين الاجتماعيين بالسعي للحصول علي دورات التتمية البشرية التي تثقل من

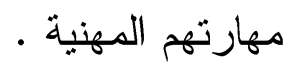
ـ. السعي لتوضيح دور الأخصائي الاجتماعي داخل مدارس التعليم الفني بما يحقق الرضي الوظيفي له وان يفهم طبيعة عملة . ه. العمل علي إعداد الأخصائيين الاجتماعيين إعداد مهنياً قوي حتى بستطيعوا التغلب علي الضغوط الاجتماعية. 7. أن تكون هناك دور ات تدريبية ولقاءاء مهنية بصورة منتظمة تحقق التفاعل بين الأخصائيين الاجتماعيين ومهنياً و علمياً. V.أن يحتوي المقرر التدريبي أو المدرسي علي جز و يوضئح كيفية العمل مع الضغوط بكافة أنو عها.

\section{المراجع}




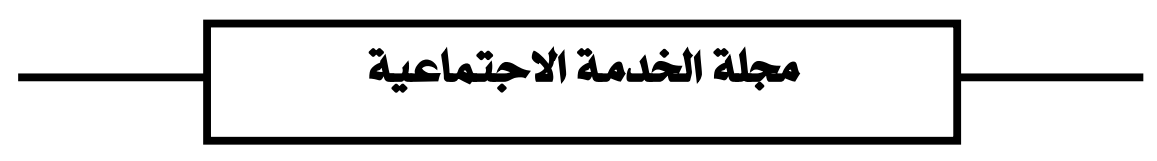

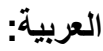

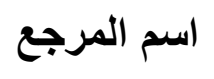

أحمد محمد نصر: تقييم المهارات المهنية لاى الأخصائيين الاجتماعيين في ضوء

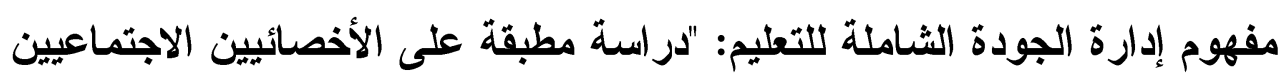

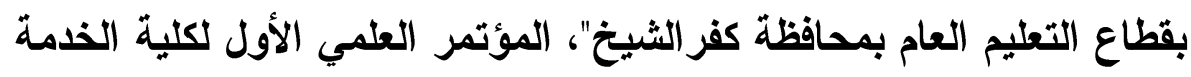

$$
\text { الاجتماعية - جامعة أسيوط ، } 1 \text {. . . ب. }
$$

أحمد حسن عبد الرازق ، بحث بعنوان " الحاجات الإثر افية لتطوير الأداء المهني

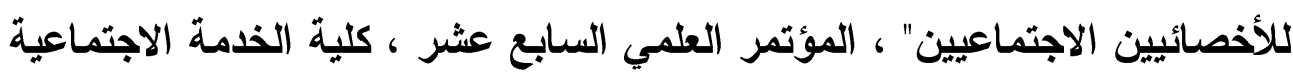

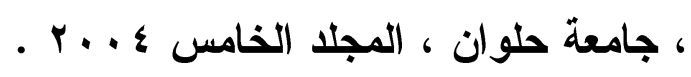

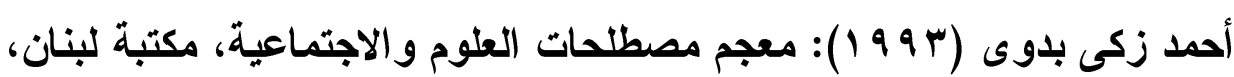

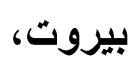

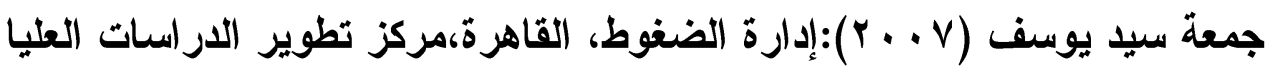

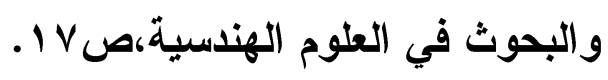

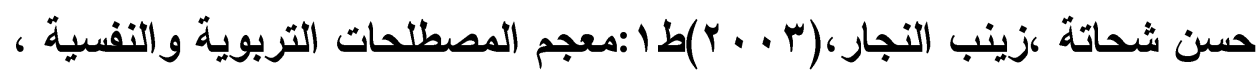
الادار المصرية اللبنانية، القاهرة.

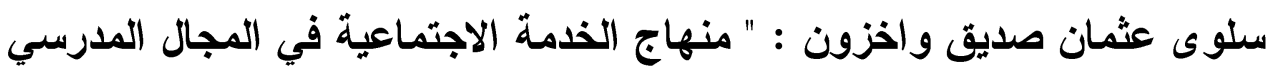

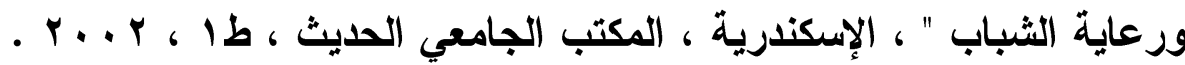

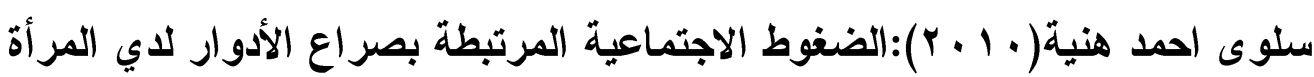

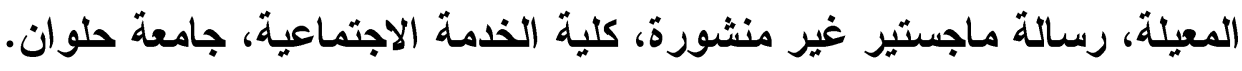

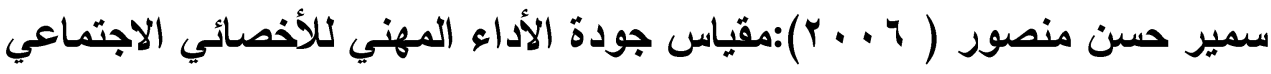

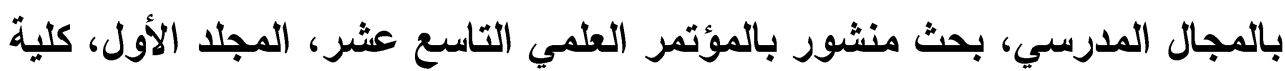

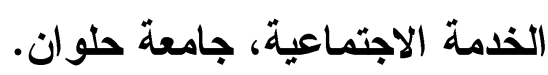

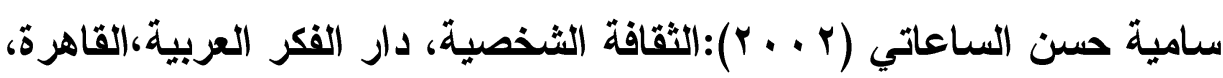

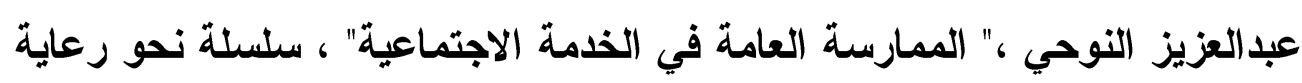

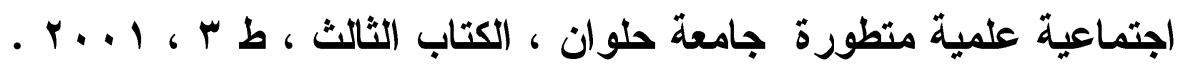

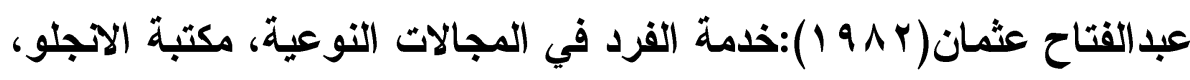

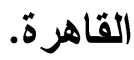

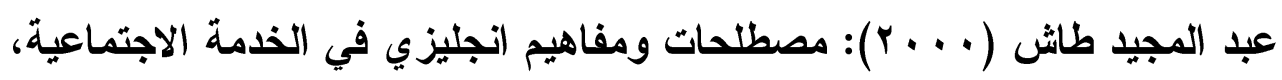

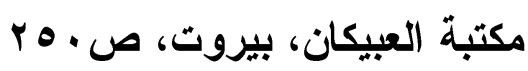




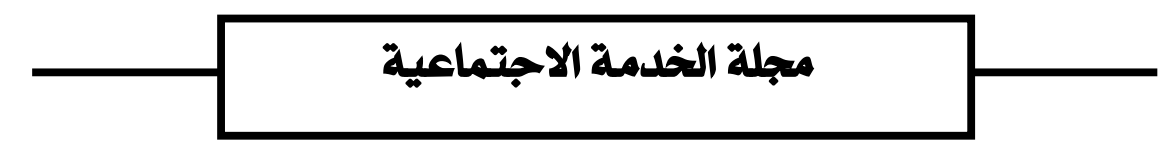

rا

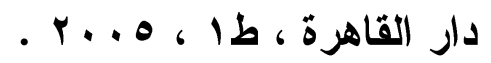

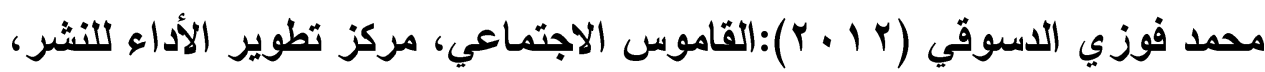

العدد الخامس، ص \& 1.

طلعت منصور (991 (99): قائمة الضغوط النفسية للمعلمين، مكتبة الانجلوا

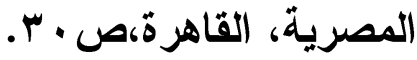

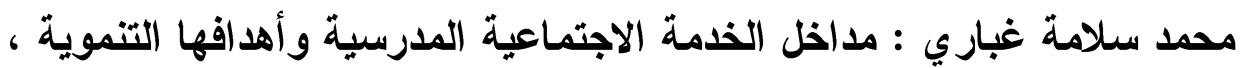

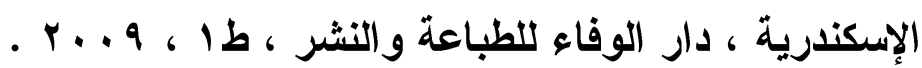

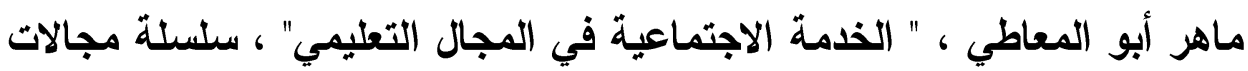

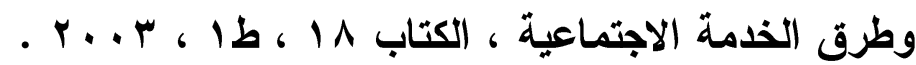

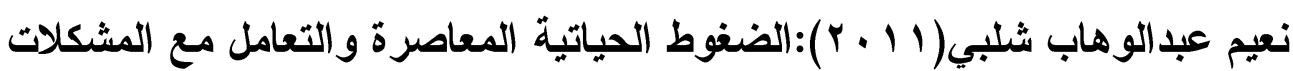

الفردية والأسرية ، المكتبة المصرية، المنصورة المبندة

مالكوم باين ،ترجمة:حمدي منصور ،سعيد عويضة ( r):نظرية الخدمة

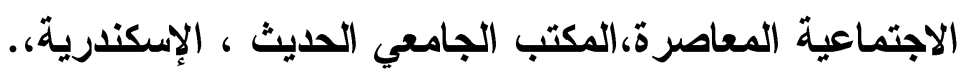

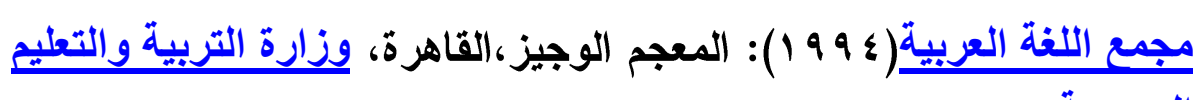

المصرية

محمد سعيد فراج (0 . . r):البناء الاجتماعي والثخصية،دار المعرفة الجامعية،

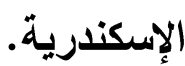




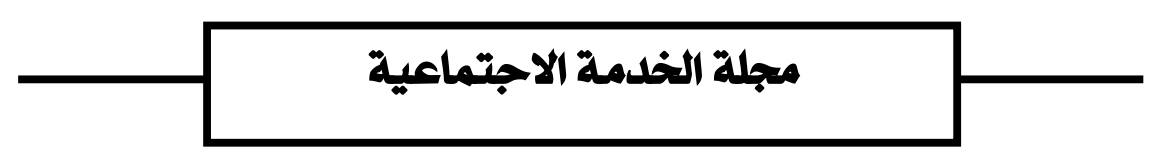

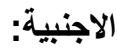

rr N A S W (2013), STANDARDS for Social Work Case Management

rr N A S W (2000), Standards for Social Work Practice in HealthCare Settings.

I\& Schuurman, Shelley D(2008), An exploration of the individual characteristics and abilities that contribute to competent professional performance in social work practitioners, Michigan State University, $\mathrm{Ph}$.

ro Lackey, Benjamin ( 2005):Introduction to Psychology of tests practice, U.S.A, wee Brown communications, inc.p3. 